\author{
WALDEN \\ UNIVERSITY \\ A higher degree. A higher purpose.
}

Walden University ScholarWorks

Walden Dissertations and Doctoral Studies

2010

\title{
The use of human patient simulators to enhance the clinical decision making of nursing students
}

Sharon Kay Powell-Laney

Follow this and additional works at: http://scholarworks.waldenu.edu/dilley

This Dissertation is brought to you for free and open access by the Walden Dissertations and Doctoral Studies Collection at ScholarWorks. It has been accepted for inclusion in Frank Dilley Award for Outstanding Doctoral Study by an authorized administrator of ScholarWorks. For more information, please contact ScholarWorks@waldenu.edu. 


\title{
Walden University
}

\author{
COLLEGE OF EDUCATION
}

This is to certify that the doctoral study by

\section{Sharon Laney}

has been found to be complete and satisfactory in all respects, and that any and all revisions required by the review committee have been made.

\author{
Review Committee \\ Dr. Cheryl Keen, Committee Chairperson, Education Faculty \\ Dr. Kelly Hall, Committee Member, Education Faculty \\ Dr. Karen Hunt, University Reviewer, Education Faculty
}

\author{
Chief Academic Officer \\ David Clinefelter, Ph.D.
}

Walden University

2010 


\begin{abstract}
The Use of Human Patient Simulators to Enhance the Clinical Decision Making of Nursing Students by Sharon Kay Powell-Laney RN, MSN

MSN, Indiana University of Pennsylvania, 1996 BSN, Indiana University of Pennsylvania, 1987

Doctoral Study Submitted in Partial Fulfillment of the Requirements for the Degree of Doctor of Education Administration Leadership for Teaching and Learning
\end{abstract} Walden University August 2010 


\begin{abstract}
One of the newest teaching modalities in nursing education is the use of human patient simulators (HPS). An HPS simulation scenario creates a software program vignette in which students interact with a manikin to practice caring for critical patients in a risk-free environment. Although used extensively in schools of nursing, there is little research that examines if these expensive simulators improve the clinical decision-making ability of nursing students. The purpose of this experimental differentiated treatment study was to assess if HPS technology leads to increased clinical decision-making ability and clinical performance more than the teaching modality of a paper and pencil case study. Students ( $n=133)$ from practical nursing programs in Pennsylvania were randomly assigned to one of 2 groups learning about the care of a patient with a myocardial infarction: an HPS simulation group or a paper and pencil case study group. One-tailed, independent $t$-tests were used to measure pre and post treatment exam and clinical performance scores measuring the care of a patient with a myocardial infarction. Results indicated that there was a statistically significant learning gain from the use of HPS technology compared to the paper and pencil case study $(p<0.001)$. Students in the HPS simulation group also performed CPR more quickly than students in the case study group $(p<0.001)$. The research adds a rare control group study to the literature and confirms previous findings about the effectiveness of HPS technology. Nurse educators can benefit as the results validate the use of HPS technology in nursing education. Ultimately patients may benefit from increased quality and speed of care from practical nurses whose training was improved through the use of HPS technology.
\end{abstract}



The Use of Human Patient Simulators to Enhance the Clinical Decision Making of Nursing Students by Sharon Kay Powell-Laney RN, MSN MSN, Indiana University of Pennsylvania, 1996 BSN, Indiana University of Pennsylvania, 1987

\section{Doctoral Study Submitted in Partial Fulfillment} of the Requirements for the Degree of Doctor of Education

Administration Leadership for Teaching and Learning

Walden University

August 2010 
UMI Number: 3418985

All rights reserved

INFORMATION TO ALL USERS

The quality of this reproduction is dependent upon the quality of the copy submitted.

In the unlikely event that the author did not send a complete manuscript and there are missing pages, these will be noted. Also, if material had to be removed, a note will indicate the deletion.

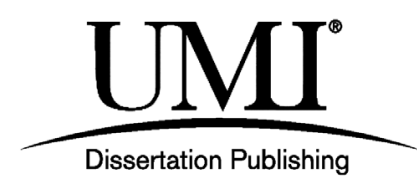

UMI 3418985

Copyright 2010 by ProQuest LLC.

All rights reserved. This edition of the work is protected against unauthorized copying under Title 17, United States Code.

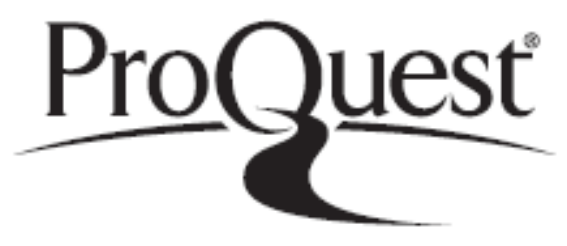

ProQuest LLC

789 East Eisenhower Parkway

P.O. Box 1346

Ann Arbor, Ml 48106-1346 


\section{Table of Contents}

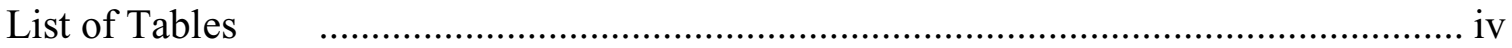

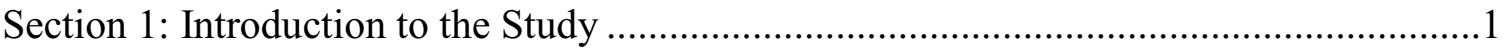

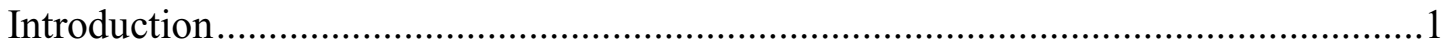

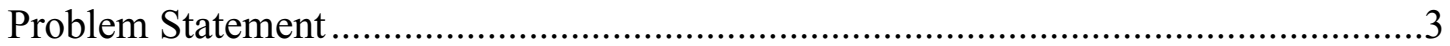

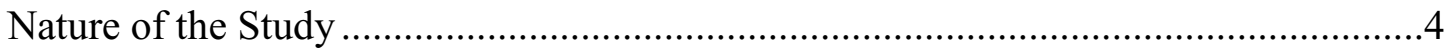

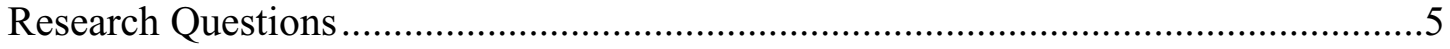

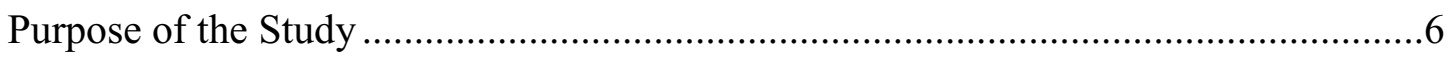

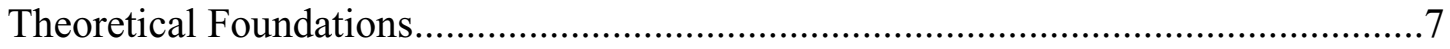

Traditional Nursing Education.................................................................. 9

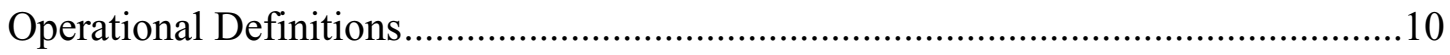

Assumptions, Limitations, Scope, and Delimitations of the Study ..........................11

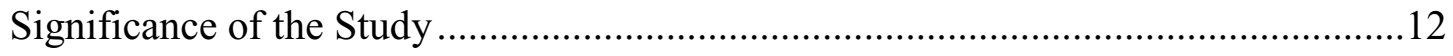

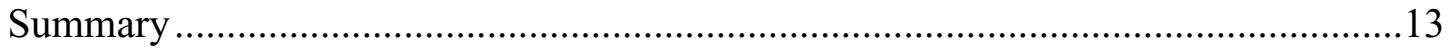

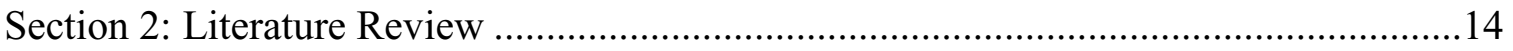

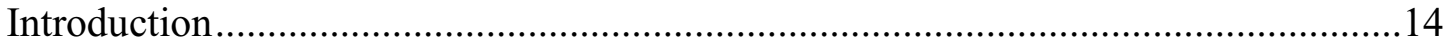

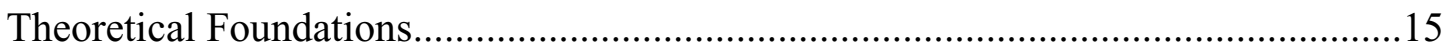

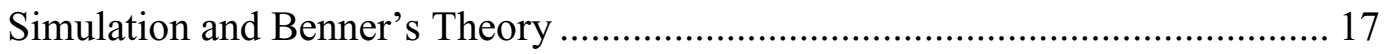

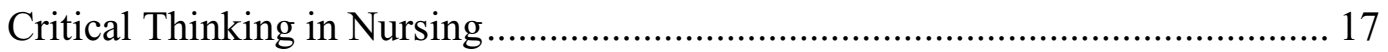

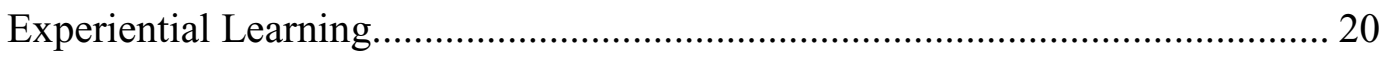

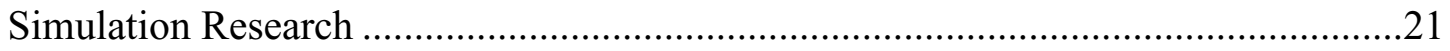

Simulation in Non Nursing Education ............................................................ 21 


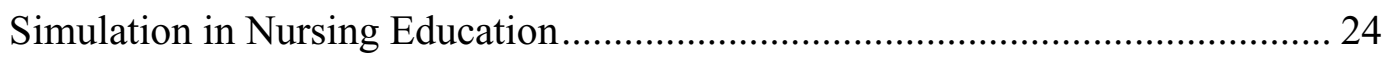

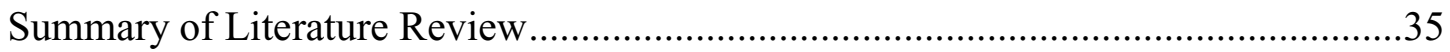

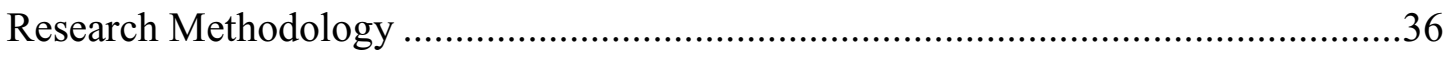

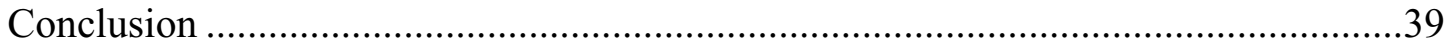

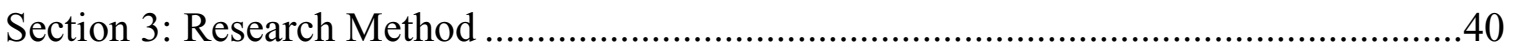

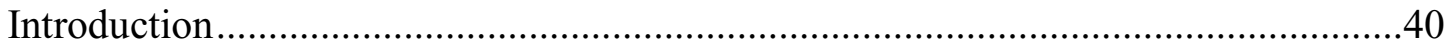

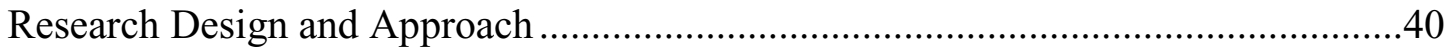

Experimental Method........................................................................... 41

Differentiated Treatment Experimental Design............................................ 42

Sample43

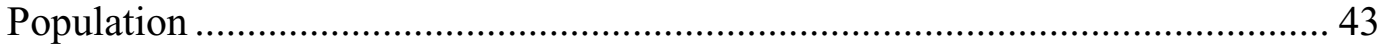

Sample44

Sampling Methods and Assignment to Treatment........................................... 45

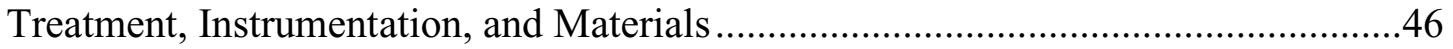

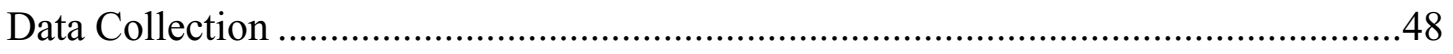

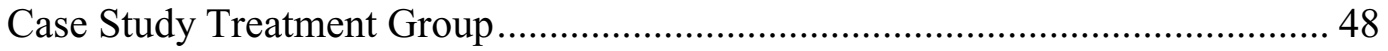

Simulation Treatment Group .............................................................. 49

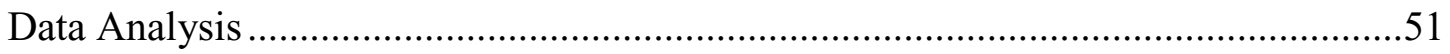

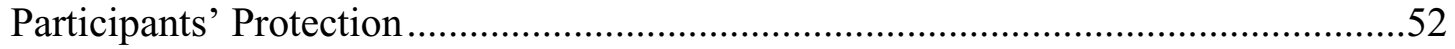

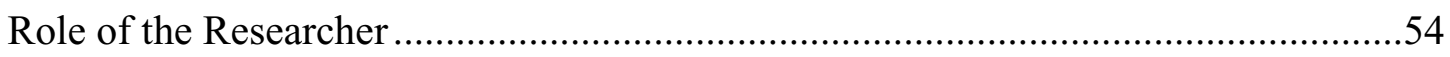

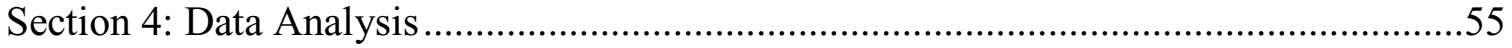

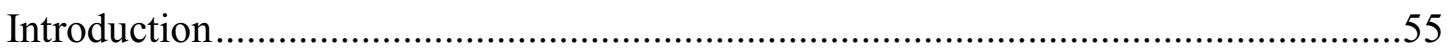




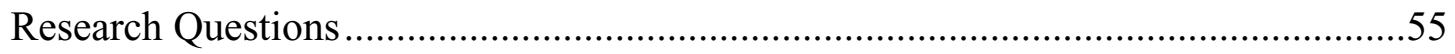

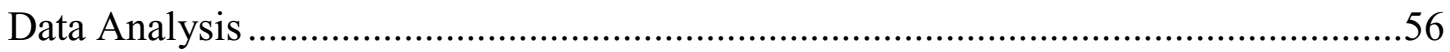

Research Question 1: Interpretation of Findings ................................................ 56

Research Question 2: Interpretation of Findings .................................................5 58

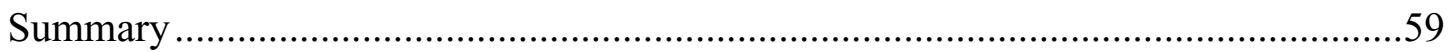

Section 5: Conclusion and Recommendations for Further Study .....................................60

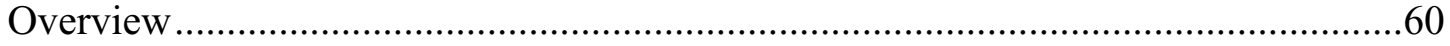

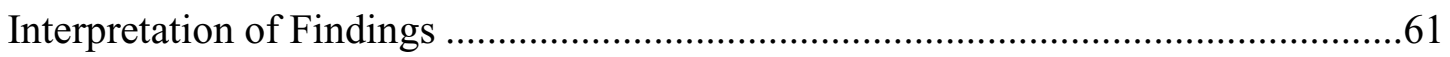

Research Findings and Theoretical Framework …….......................................... 62

Research Findings and Previous Nursing Simulation Research........................... 63

Implications for Social Change ...........................................................................65

Recommendations for Action .........................................................................66

Recommendations for Further Study ………........................................................66

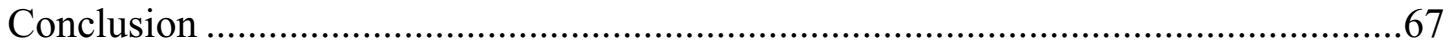

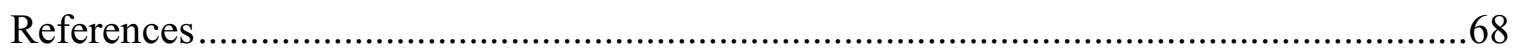

Appendix A: Pre test: Care of the Patient Experiencing a Myocardial Infarction..............74

Appendix B: Case Study: Care of the Patient Experiencing a Myocardial

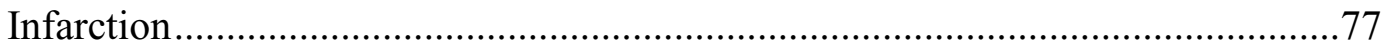

Appendix C: Post Test: Care of the Patient Experiencing a Myocardial Infarction..........79

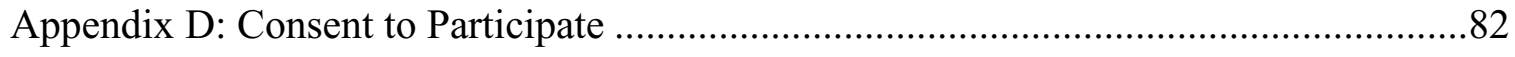

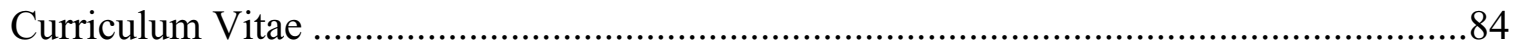




\section{List of Tables}

Table 1. Research Activities by Group ..................................................................... 50

Table 2. Pre and Post Test Percentage Scores ........................................................... 57 
Section 1: Introduction to the Study

Human Patient Simulation (HPS) is a teaching method widely used in practical nursing education. Nurse educators have embraced HPS as an effective method for teaching critical thinking and clinical decision-making without a large body of quantitative research studies to support its use.

\section{Introduction}

Nursing is a caring profession and the primary impetus for this inquiry is the hope of understanding how effective simulation can be in the preparation of students to become competent in caring for society. Though the community of nurse educators has embraced the use of human patient simulators to teach clinical decision-making to nursing students (Jeffries, 2008), there is a gap in the literature on the effectiveness of using simulators to teach clinical decision-making skills.

The implied intent of using a human patient simulation experience is to increase the transfer of learning to actual patient care experiences. The simulation is a high fidelity depiction of a scenario that nurses may encounter with their patients in the hospital or nursing home setting. The student must act and react to the simulated patient as if the situation were actually occurring. During the scenario, the nursing students develop skills they will need when they encounter a similar situation in a real-world environment. The more well-designed the patient care scenario, the better able the students will be to apply those skills and abilities to a real-world situation (McArthur Ravert, 2004).

The use of simulators in training programs is not new. The aviation industry first began using flight simulators in the 1950 s to train pilots to respond to problems they 
might encounter while in real flight situations (Gordon, Issenberg, McGaghie, Petrusa, \& Scalese, 2005). The pilots could "practice" how they would respond to critical situations in a risk-free, safe environment. In the medical field educators began to teach anesthesiologists how to manage complex patient problems using a simulator (Gordon, Issenberg, McGaghie, Petrusa, \& Scalese, 2005). Although nothing compares to the "real world" experience of actual clinical practice, high fidelity simulators can be used to train professionals how to react to critical incidents in an environment where there is no actual risk to individuals.

Pilot training using simulation technology contributed to the successful landing of US Airways flight 1549 on January 15, 2009. Captain Chesley B. "Sully” Sullenberger was able to land his aircraft on the Hudson River after it was hit by a flock of birds. All 155 individuals on the flight survived the landing. While Captain Sullenberger attributed his successful water landing to his experience as a pilot in the Air Force, he had never before conducted a water landing, which might suggest that his simulated pilot training contributed to the "Miracle on the Hudson" (MSNBC, January 15" 2009 ).

Much like aviation and aeronautics, healthcare is considered a high-hazard industry. Gaba (2007) contended that healthcare providers solve problems like pilots, approaching the usual problems in the usual ways. Therefore, repetition of varying nuances of the same problem (such as caring for a patient with a myocardial infarction) should increase the ability of the healthcare provider to respond quickly to common problems and be able to adjust for differences in each clinical scenario. According to Jeffries (2008) the nursing education community has so embraced simulation technology 
that state boards of nursing are considering allowing the time spent teaching simulation experiences to count towards the total number of hours that nursing students must "practice" in a clinical environment.

Nursing faculty have begun to publish small research studies conducted with their students while using simulation technology. Most of these small, classroom studies have focused on knowledge acquisition and have indicated that simulation is an effective teaching modality in nursing education (Comer, 2005; Jeffries \& Rizzolo, 2006; Ellis, Lashley, \& Nehring 2002). However, Jeffries (2008) suggests that more research (using larger sample sizes) should be conducted to validate these results.

Nurse educators need teaching methods that challenge and stimulate the interest of all nursing students. The millennial generation of students is technologically advanced and use of simulation technology allows the student to practice on a high fidelity manikin while eliminating risks to actual patients. Although simulation has been used in nursing education for over 10 years there is still a lack of research on the actual efficacy of the technology in increasing clinical decision-making ability of nursing students.

\section{Problem Statement}

Nursing programs have been using simulation technology for over a decade to teach nursing students to make better clinical decisions. Despite this change in educational practice, there is a gap within the literature in nursing education regarding the value of HPS as a teaching method. Research needs to be conducted to evaluate the efficacy of simulation in increasing the clinical decision-making ability of nursing students. The community of nursing education needs to validate the effectiveness of this 
highly expensive, labor-intensive teaching modality. Is the teaching method worth the time, energy, and money the nursing community is currently spending? Will teaching methods using simulation actually improve the ability of the student to make better clinical decisions and allow them to function effectively in the healthcare industry?

The large community of practice of nurse educators advocate for the use of simulation as a teaching modality that shows evidence for increasing clinical decisionmaking: however simulation is widely used without a large body of evidence to support it (Jeffries, 2008). The maintenance, training of staff, and upgrading of the computer applications is extensive. Unbiased research demonstrating if simulation technology is effective is needed so nurse educators are better informed when making decisions about this expensive teaching tool.

\section{Nature of the Study}

The research project is a quantitative, experimental, differentiated treatment design (Hadley \& Mitchell, 1995). The study investigates the use of simulation technology in assisting nursing students to develop clinical decision-making skills they will need to use in a real-world, clinical environment.

The 133 participants in the study, encompassing five different practical nursing classes at four different nursing schools, were randomly assigned to either a case study group or a simulation group. The independent variable in the study was the method used to teach care of a patient having a myocardial infarction: either traditional paper and pencil case study or high fidelity simulation scenario. The dependent variables were clinical decision-making ability (as measured by multiple choice exam scores concerning 
treatment and care of a patient having a myocardial infarction) and clinical performance (as measured by speed in performing cardiopulmonary resuscitation during a simulation scenario).

Demographic information concerning student gender, age, and experience with simulation technology was collected on the pre test form in order to describe the sample of nursing students. The case study group completed a traditional paper and pencil case study concerning care of a patient with a myocardial infarction. The simulation group participated in a simulation scenario that was equivalent in content to the paper and pencil case study. Both groups needed to use decision-making skills to effectively care for a patient suffering from a myocardial infarction.

A post test exam measuring care of a patient experiencing a myocardial infarction was given to both treatment groups. Immediately following the post test exam both groups separately engaged in the same simulation experience in which the simulation group previously took part.

Comparison of pre test and post test scores on a multiple choice exam, and clinical performance evaluation scores between the two groups was conducted using a one-tailed independent measures $t$-test. More detailed information concerning methodology will be included in section 3 and data analysis will be covered in section 4 .

\section{Research Questions}

Research questions for the study include: 
1. Do nursing students taught through pedagogy using a simulator make better clinical decisions than nursing students taught through pedagogy using a paper and pencil case study?

2. Do nursing students taught through pedagogy using a simulator perform cardiopulmonary resuscitation faster than nursing students taught through pedagogy using a paper and pencil case study?

The null hypothesis for Research Question 1 was: There is no difference between the clinical learning gains of students taught through pedagogy using a simulator and nursing students taught using a paper and pencil case study. The alternative hypothesis was: There is a significant positive difference in the learning gains of nursing students taught through pedagogy using a simulator compared to students taught using a paper and pencil case study.

The null hypothesis for Research Question 2 was: There is no difference in time to cardiopulmonary resuscitation of nursing students taught through pedagogy using a simulator and nursing students taught using a paper and pencil case study. The alternative hypothesis was: There is a significant negative difference in time to cardiopulmonary resuscitation of nursing students taught through pedagogy using a simulator and nursing students taught using a paper and pencil case study.

\section{Purpose of the Study}

The purpose of the study was to ascertain whether the use of HPS technology in nursing education can increase the clinical decision-making ability of nursing students. There is a lack of evidence to support using simulation technology to teach clinical 
decision-making in nursing students. Simulators are expensive, costing between $\$ 45,000$ $\$ 85,000$, and labor intensive for nurse educators to learn about, set-up, and maintain for classroom use. The learning curve for faculty to program the simulators is very high (Jeffries, 2008). Nursing faculty members are hesitant to invest time and energy into a teaching pedagogy that has not been proven to be any more effective than traditional lecture and case studies to teach application of nursing content. The community of nurse educators needs evidence of the effectiveness of simulators in order to assimilate new pedagogies into a nursing curriculum.

\section{Theoretical Foundations}

Critical thinking has been addressed in the nursing literature for over 20 years. Nursing authors often use the terms clinical reasoning, clinical decision-making, and clinical judgment as synonyms for critical thinking (McArthur Ravert, 2004). The term expert or excellent nurse is found in the literature to denote those nurses who are able to prioritize patient situations-in other words, nurses who use critical thinking to guide their practice.

In the landmark book From Novice to Expert: Excellence and Power in Clinical Nursing Practice (1984), Patricia Benner postulated a theory based on the Dreyfus model of skill acquisition. This is a situational skill acquisition model that holds that because each situation differs from another, the clinician can only be judged by the outcome of the situation. Benner used this model to describe how an increase in knowledge and experience assist the nurse in becoming an expert nurse, whose traits are characteristic of a critical thinker. Expert nurses are able to quickly manage a patient care problem 
because they have had many years of patient care situations in which they can relate the aspects of the current patient situation. Expert nurses are sometimes referred to as having an intuitive "sixth sense" for knowing when patients are in imminent danger; in reality they are able (as Benner's theory suggests) to isolate and prioritize assessment data that novice nurses are unable to discern.

Benner's (1984) theory has been used as the basis for many research studies. For example Hicks (1997) found that decision-making in nurses increased with years of patient care experience and Martin (2002) found that critical thinking and clinical nursing expertise increased with the age of the nursing student and his or her clinical experience but did not increase with progression through nursing school.

Many nursing programs have used Benner's theory to develop curriculum and teaching strategies to assist individuals to become critical thinkers. Nurse educators should use teaching strategies that foster clinical decision-making skills in nursing students. From Benner's theory, it appears as if a problem-based learning style would lead to the type of reflective reasoning that contributes to the development of critical thinking skills. Schon (1984) described this type of decision-making as "reflection in action" (p. 267). Teaching modalities that increase this type of behavior should be used in nursing education. Castillo (2006) used problem-based learning theory to design case studies that enhance the critical thinking skills of nurses and nursing students. Within these case studies are exercises that require interpretation, analysis, inference, and prioritization of data, and then implementation of nursing actions, followed by the evaluation of outcomes. 


\section{Traditional Nursing Education}

Traditionally, nursing education has focused on teaching theory and skills separately (Jeffries, 2008). The student is then expected to use this information in the clinical setting to make critical decisions concerning patient care. In this approach, the student very rarely has the opportunity to develop clinical decision-making ability within a safe environment

Changes in the healthcare industry over the past decade, has led to many challenges for nurse educators. The nursing shortage has led to higher patient-to-nurse ratios. The lack of nurses has led many hospitals to close, or decrease the number of staffed beds. These problems have led to a decrease in the number of clinical sites available for nursing education programs. There are also fewer nurses available in hospitals to act as role models for nursing students.

Within the Commonwealth of Pennsylvania, the State Board of Nursing (2008) recommended that $60 \%$ of the practical nursing curriculum be devoted to actual clinical practice. However, meeting this recommendation is problematic because of a critical shortage of nursing instructors in the United States, and the availability of clinical sites for practice is also decreasing (Jeffries, 2008). The nursing education community is faced with a critical need for nurses, with few nursing instructors, and fewer hospitals in which the students can practice their profession. With the use of simulation equipment, studentfocused learning becomes the method of instruction. Most state boards of nursing allow a portion of the clinical practice (usually done in a hospital or other clinical facility) to be completed in a simulation lab (McAruther-Ravert, 2004). However, Schott-Baer \& 
Touriniemi (2008) found that the simulators are very technologically advanced and require a great deal of faculty training in order for them to be used to their maximum benefit.

\section{Operational Definitions}

The following terms will be used throughout the study:

Clinical decision-making ability and clinical reasoning: the ability of the nursing student to manage and prioritize patient care using critical thinking skills.

High fidelity: pertains to a high degree of realism in a patient care situation.

Human patient simulation technology: the use of high fidelity manikins to teach nursing students how to manage patient care in a risk-free environment. Manikins are computerized to mimic signs and symptoms of actual patients with a high degree of realism (McArthur-Ravert, 2004).

Scenario: a vignette; computer simulation is used to design a staged scene depicting a patient with the symptoms of a certain disease (in this case a myocardial infarction or heart attack). The student must design care for the manikin as if it were an actual patient. Case Study: a traditional paper and pencil case study in which the student must describe the care for a patient with a particular malady, in this case a patient with a myocardial infarction.

Debriefing: the time after a scenario when nursing students review the scenario and provide reflection on nursing actions during the scenario.

Myocardial infarction: condition characterized by lack of blood flow to the heart resulting in chest pain and death of heart tissue; heart attack. 


\section{Assumptions, Limitations, Scope, and Delimitations of the Study}

Nurse educators assume that the use of simulation technology will increase the ability of nurses to make better clinical decisions. Current evidence reveals there is a gap in the literature that would provide a positive correlation between increased critical thinking skills (clinical decision-making) and HPS technology in a large sample size of nursing students. Many of the studies that have been done have been in the authors' own schools of nursing where biases might have existed and the number of nursing students was not large enough to provide any useful statistical knowledge that could be generalized to the larger population of nursing students. The only large-scale study completed did not use increased critical thinking skills, or clinical decision-making, as an outcome. Section 2 will address studies conducted in simulation technology.

The study is limited to a representative group of practical nursing students from western and central Pennsylvania at the same point in their one year of education. Generalizing the results of the study to all practical nursing students in all states may be difficult, although the scenario, case study, presentation, and pre and post tests could be used in any nursing program in the United States.

The assumption that the hypothesis, that simulation technology improves the clinical decision-making ability of nursing students, can be measured through a research study designed to measure the clinical decision-making ability of nursing, may be false. There may be more accurate methods to ascertain whether simulation is an effective teaching modality. 
Other threats to validity include: (a) The instruments (pre and post test exams concerning care of the patient experiencing a myocardial infarction, and clinical performance exam) may not be able to adequately measure clinical decision-making ability of the student nurses; and (b) the scenario and case study used may not accurately represent care of the myocardial infarction patient. External validity may be affected by students having differing levels of clinical experience. Students may answer questions based on past clinical experience rather than information they garnered during the presentation, case study, or scenario, thereby affecting external validity of results.

\section{Significance of the Study}

Patient safety is of utmost importance in nursing education. Nurses are charged with the concept of "do no harm" and the advent of simulation technology has assisted nurse educators in finding a high-fidelity environment where nursing students can make, correct, and learn from their mistakes without the danger of harming live patients (Peteani, 2004). This study sought to validate the use of simulation technology as a teaching method, instructing students in the care of a patient having a myocardial infarction. Nurse educators can use the results of the study to determine if their schools should invest in simulation technology or how much simulation time they should include in their curriculum. Many traditional nurse educators have difficulty embracing technology without a large body of research that validates the time and energy needed to design and implement simulation scenarios.

Nursing has always been one of the most trusted professions and patients trust that the nurse they have caring for them has the skill set necessary to assist them in their 
recovery. Teaching methods that increase the ability of the nurse to manage patient care should be used as much as possible in nursing education.

Benner (1984) asserted that only through years of experiencing the same type of patient care scenarios will the nurse establish expertise in his or her field. Nursing educators can "simulate" those experiences and hopefully increase those decision-making abilities of student nurses in a risk-free environment while they are still in nursing school.

\section{Summary}

Nurse educators have been using simulation technology to teach nursing students how to manage and prioritize patient care. The assumption that the use of simulation technology results in a more clinically competent nurse has not been examined to the extent necessary for confident adoption of simulation as a teaching method. This experimental, quantitative differentiated treatment research study measured the efficacy of simulation technology when compared to a traditional paper and pencil case study. The results of the research will lend to the body of knowledge concerning simulation technology as a valid teaching method.

Section 2 will explore the theoretical foundations for the study and review the body of literature concerning simulation in various types of education. Section 3 will address the design of the study. Section 4 will describe the data analysis of the study and section 5 will present conclusions and recommendations for further study. 
Section 2: Literature Review

Introduction

The focus of this research study concerned using human patient simulators to teach clinical decision-making to nursing students. Although the use of high-fidelity simulators appears to be the wave of the future in nursing education, the research studies completed on the effectiveness of simulation to teach clinical decision-making skills in nursing education are sparse. Many of the studies reviewed (Arundell, Ciofi, \& Purcal 2005; Comer, 2005; Simones, 2008) have had very small sample sizes and focused on the students' perception of or feelings towards using simulation in their education.

This review of the literature establishes a theoretical basis for the research study, evaluates findings of existing studies, and evaluates the type of research studies that have been conducted concerning simulation technology. An initial database search (ERIC and EBSCO) using Walden University Library and the keywords simulation, critical thinking, clinical decision-making, nursing, and quantitative research resulted in a small number of relevant articles. Further searches conducted using the keywords simulation, evaluation, and performance revealed a small body of quantitative research studies conducted in aeronautics and medicine which are included in this review. The intent of this quantitative research project was to provide information on the value of using human patient simulation technology to teach clinical decision-making skills in practical nursing students. 


\section{Theoretical Foundations}

Over the years, nursing theorists have attempted to describe the process by which nurses learn to make life-saving clinical decisions for their patients. Nurse educators attempt to provide students with teaching modalities that foster their ability to acquire the ability to make sound clinical decisions.

\section{Patricia Benner: From Novice to Expert}

The guiding theorist for this research project is Patricia Benner (1984), who postulated that nurses learn to care expertly for patients through a process of experience and reflection. Benner conducted descriptive research funded by the Department of Health and Human Services to develop methods of evaluation for nurses in nursing schools, and in the hospital setting. The method for the research was to conduct paired interviews with newly graduated nurses and their preceptors. Benner also interviewed 51 nurses considered to be expert by hospital administrators, a group of 11 recently graduated nurses, and 5 nursing students. Interviews were analyzed for key themes and domains in nursing practice. Benner found that expertise was situational. If an expert nurse in obstetrics were to move to a different floor of the hospital she would not be an expert on the new unit until she had acquired the ability to recognize the nuances of the particular patient encounters on that new unit. The nurse would be merely competent for a time on that new unit, until she had acquired enough experience to achieve expert status.

Benner (1984) applied the themes derived from her research to the Dreyfuss model of skill acquisition (1980), a model developed by the authors, Dreyfuss and 
Dreyfuss, after studying pilots and chess players. The authors postulated that pilots become experts at their craft by acquiring skill sets over time, through experience. Benner was able to apply specific nursing competencies she identified in her research to the Dreyfuss model. Her research led her to the assumption that experience is a requisite for expertise and she promulgated a theory that identifies the specific characteristics necessary for a nurse to progress from novice to expert status.

Benner (1984) identified the specific skills of each level. Novice nurse base their clinical decisions on rules and regulations. Their behavior is characterized by inflexibility and rigidness in thought. Novice nurse merely responds to the stimuli around them. Advanced beginner nurses begin to recognize aspects of a situation from past experiences, but still remains governed by rules as they become more flexible in their thinking. Advanced beginners learn best by repetition. Nurses can become competent after 2-3 years of experience working in the same type of nursing unit. These nurses begin to formulate plans for their actions and have become very efficient and organized in their thinking. They still lack speed and flexibility. Benner postulated that this group benefits the most from simulations.

Proficient nurses perceive situations as a whole and are able to establish longterm goals in their thinking. They know how a typical patient situation should conclude and they evaluate each patient encounter against that typical situation or scenario. These nurses do not have enough patient care experiences to have achieved expert status. Benner (1984) theorized from the interviews that proficient nurses are best taught by case studies, in which the nurses learned to recognize the nuances of different types of patient 
encounters. Expert nurses have worked on the same type of unit an average of five years. Their behavior is not governed by rules or regulations. They are fluid and flexible in their actions and they grasp problems quickly, especially during rapidly changing situations. They anticipate problems and intervene quickly on the patient's behalf.

\section{Simulation and Benner's Theory}

Early recognition of patient problems is a hallmark of Benner's (1984) theory, and the quick detection of problems allows the nurse to move fluidly from being a novice nurse to an expert nurse. Although Benner did not address HPS technology specifically in her study, she felt that case studies and simulations would help nurses achieve expert status. Simulation technology mimics patient encounters and may assist the student/nurse to reach a higher proficiency level much more quickly than without it. One of the intents in using the simulation scenarios is to assist the students in recognizing patterns in patient behaviors. Students will remember how they reacted during a similar simulation scenario and will be able to more quickly recognize and respond to specific patient problems.

\section{Critical Thinking in Nursing}

Alfaro-LeFevre (2004) contended that critical thinking, a focus of educational research, is better characterized as clinical decision-making or reasoning in a nursing setting. When faced with a situation requiring judgment or critical thinking, the nurse decides the best outcome of a patient situation and then bases his or her choices regarding the actions that will result in that outcome. Alfaro-LeFevre's definition of critical thinking or clinical reasoning in nursing includes purposeful, goal-directed thinking that makes judgments based on evidence rather than conjecture (guesswork). Clinical 
reasoning is based on principles of science and the scientific method and requires strategies that maximize human potential and compensates for problems caused by human nature. Alfaro-LeFevre suggested that the most effective method for teaching clinical decision-making to students is through the use of case studies or situations. The student who can prioritize the elements of a patient situation or scenario is using inference, deductive reasoning, and reflective evaluation, and will become an expert practitioner. Alfaro-LeFevre developed strategies to assist nurses in developing clinical judgment or clinical reasoning skills. The nurse should learn terms and concepts of the unit they work on, as well as become familiar with the normal findings of different types

of patients. The nurse should also ask why certain normal or abnormal findings occur and learn facts concerning the pathophysiology of the patient's problem.

Although Alfaro LeFevre (2004) has not addressed using simulation as a method for teaching critical thinking, she has strongly advocated for the use of case studies or scenarios to teach nurses how to critically think, contending that as nurses analyze the situation of a case study they will learn the type of deductive reasoning skills they will need to become a better practitioner.

\section{Critical Thinking and Clinical Performance}

Many students of the millennial generation are used to multi tasking, sometimes using more than one type of technology at one time (Morgan \& Pardue 2008). It is a challenge to educate nursing students who are used to being "entertained" by technology.

Nurse educators need to develop and use teaching modalities that stimulate creativity, critical thinking, and problem-solving in students (Alfaro-Lefevre, 2004). 
Lasater (2007) found that simulations and group work have been effective teaching strategies for the millennial generation. Teaching methods that promote critical thinking and clinical decision-making ability may provide the student with the skills necessary to survive in a technologically proficient society, whatever their career may be.

There is some contention regarding whether increased critical thinking (as measured by standardized critical thinking inventories) actually translates to better clinical performance (Riddell, 2007). The critical thinking that is done by nurses is at the application level (Dempsey \& Stewart 2005) and the clinical performance that stems from the application of learned content (Riddell, 2007). In a longitudinal study involving 55 students at a large university, Dempsey and Stewart (2005) found that the nursing students' critical thinking skills (as measured by the California Critical Thinking Disposition Inventory -CCTDI) did not increase as they progressed through their 4 year nursing program. Therefore, Dempsey and Stewart (2005) theorized that nursing may be using the wrong methods to evaluate critical thinking in nursing, and that perhaps the measurement of critical thinking in nursing should use context specific exams, such as the NCLEX (National Council Licensing Exam) exam given to nursing graduates seeking licensure.

The NCLEX exams test the nursing graduate at the application, analysis, and synthesis levels of thinking. The exams contain multiple choice, fill-in-the-blank drug calculation questions, and prioritizing questions. Many questions give the nursing applicant a scenario where the nurse must order the proper sequence of actions the nurse 
should take based on the patient situation. This is very similar to what a nursing student would be expected to do during a simulation scenario.

Giddens and Gloeckner's (2005) study fit within Dempsey and Stewart's (2005) recommendations regarding using the NCLEX exam as the method for evaluation of critical thinking. They found that students who passed the NCLEX-RN had higher critical thinking scores (as measured by the CCTST) than students who failed the licensure examination. In this non experimental ex-post-facto research study, data were collected from one nursing school that graduated 218 students over 3 years. None of the variablesage, gender, or nursing GPA- was positively correlated with passing of the licensure exam. Because of the convenience sampling of students in one nursing program, results from this study cannot be easily generalized to the graduate nurse population.

In a correlational study by Hicks (1997) involving a convenience sample of 54 critical care nurses from three private hospitals, the only attribute that led to increased critical thinking scores for nurses (as measured by the CCTDI) was years of critical care experience. Hicks also used gender and age as variables in the study. The author theorized that general measures of critical thinking may not be appropriate for nurses engaged in clinical practice, but the data substantiated Benner's (1984) theory that increased experience did correlate with expert status.

\section{Experiential Learning}

John Dewey (1938/1997) theorized that experience arises from the interaction of two principles, continuity and interaction. Each experience a student has will influence future interactions. Dewey believed that a student's current experience is a function of the 
interaction that occurs between their past experience and the present situation. As students interact with the environment, conflicts and problems may occur that provoke thought and reflection. As the students repeat the encounters, they are able to change their attitudes, beliefs and thoughts in order to modify their learning to the new experience. Dewey noted that using traditional methods (lecture) along with creative, intuitive, teaching modalities was the best way to teach students, rather than relying on student memorization of facts. Dewey did not discuss simulation as a teaching modality (as it was not available at the time), however simulation appears to be a progressive, creative approach for providing thought-provoking nurse-patient experiences that students can then transfer to the actual clinical arena (Schott-Baer \& Touriniemi, 2008).

\section{Simulation Research}

High fidelity, human patient simulators have been used in nursing education for approximately 10 years but other disciplines have used simulation technology for decades (Gordon, Isssenberg, McGaghie, Petrusa, \& Scalese, 2005).

\section{Simulation in Non Nursing Education}

The airline industry has used simulation to enhance the critical thinking ability of their pilots. Computer-assisted simulation in the aviation industry began in earnest in the 1950s. The philosophy behind the development of the use of simulation in aviation industry was a response to the number of lost pilots in training programs (McArthurRavert, 2004).

Decades later, after the 2003 loss of the space shuttle Columbia, the U.S. National Aeronautics and Space Administration (NASA) used simulation to prepare their 
management team to return to the space shuttle program (Klein, Parker, Salas, Stagle, \& Van Eynde, 2007). NASA embarked on a week- long simulation training for the upcoming Discovery space shuttle mission. Twenty-nine members of the space shuttle crew participated in this training. Seven key competency areas were addressed before and after the training simulation. NASA found that team members improved in efficacy, motivation, and readiness for flight $(p<.05)$. It was found from this study that NASA needed to improve communication between the space shuttle mission members. Changes were made in organizational structure from the results of this study and in July 2005 , NASA launched the successful Space Shuttle Discovery.

Gaba (2007) was a key stakeholder in developing simulation for medical education. Anesthesiology was the first medical discipline to effectively use simulators. The simulators could be programmed to mimic a myriad of patient responses to anesthesia. Gaba found that anesthesiologists used a precompiled knowledge base, derived from experience treating patients with anesthesia. Most operations were routine, but when a special circumstance or emergency developed, the anesthesiologist had to rely on past experiences to bring the patient back from the brink of death. Simulations allowed the anesthesiologist to "practice" in a safe environment with a manikin for life threatening patient encounters (Issenberg \& Scalese, 2008).

In a review of the literature addressing the use of simulation as an evaluation tool for emergency medicine residents, Bond and Spillane (2002) concluded that simulation is a useful tool in evaluating psychomotor skills, physical assessment skills, and communication skills. The authors called for standardization of evaluation instruments. In 
a study conducted by Boulet et al., (2002), in which the purpose of the study was the examination of simulation as an evaluation tool, 64 medical students participated in an evaluation simulation scenario. The students were evaluated on their performance using a checklist scored by three expert doctors and one expert nurse. The checklist contained important objectives of the curriculum essential for graduation including: thought process, actions, integration, and overall performance. Researchers found that the raters were highly consistent in their assignment of scores and concluded that reliable and valid measures of clinical performance can be obtained by using carefully crafted scenarios and checklists.

Dillon, Kaplan, and Noble (2009) studied the interdisciplinary collaboration between nursing and medical students during a mock cardiac arrest. A pre test and post test design was used to assess students' perceptions of interdisciplinary collaboration during a simulated cardiac arrest. The convenience sample contained 40 students who completed both the pre and post tests. Data analysis revealed that the medical students had a significant difference in their post test scores in regards to collaboration and nursing autonomy. The medical students perceived the nurses' role during the cardiac arrest as more autonomous, and they viewed the nurse as a collaborator in decisionmaking. The authors concluded that more simulations should involve students of differing healthcare disciplines.

Kobulinsky, McKaveney and Seybert (2008) studied the effects of incorporating simulation into a pharmacotherapy course for pharmacy students. The researchers devised a simulation to teach the students the complex skill of dysrhythmia management 
in patients with cardiovascular disease. Researchers delivered a pre and post simulation exam to each group of students participating in the simulation. Post simulation scores on cardiovascular rhythm management increased significantly and the study revealed that $67 \%$ of the 102 students achieved a $95 \%$ or higher grade in the entire pharmacotherapy course.

\section{Simulation in Nursing Education}

Simulation experience is a situation where student nurses role play situations in a patient-care scenario. Nursing instructors have used role play using low fidelity manikins for many years. Affordable, high fidelity simulators have only been available to nursing schools for 10 years. Faculty in schools of nursing have begun to publish small research studies they have conducted with their students while using high fidelity simulation technology.

In response to the trend in using simulation in lieu of traditional clinical, the National Council of State Boards of Nursing (NCSBN) developed a pilot study to investigate the effect of simulation on nursing students' knowledge, performance, and confidence (Coke, Hicks, \& Li, 2009). NCSBN develops the NCLEX or, as it is commonly known, the "state board exam". Two cohorts of 58 senior-level baccalaureate students (from the years 2006 and 2007) who were enrolled in a required critical care course at Rush University College of Nursing were asked to participate. The students were randomly assigned to one of three six-week practicum experiences. The first group had a traditional clinical hospital assignment without simulation. The second group had only simulation and no corresponding clinical experience. The third group had simulation 
and clinical experience. The researchers used written examinations before and after the clinical/simulation experience to assess knowledge acquisition. Clinical performance was assessed based on the students' behaviors during three standardized patient care scenarios. Faculty evaluated the students' simulation experienced based on if they asked focused, appropriate questions; if they identified the patient problem and performed appropriate physical assessments to confirm the identified problem; if students performed appropriate interventions; and if the students evaluated their own performance. Finally, self-confidence was assessed using a Likert-type self-confidence scale. Students were asked to self-report how confident they were in accurately recognizing a change in a patient's condition and performing basic physical assessments. The students also evaluated how confident they were in identifying correct nursing interventions and evaluating the effectiveness of interventions that were performed for the patient.

While students in the simulation and the clinical/simulation group did have a statistically significant increase in their confidence in taking care of patients with acute changes in their condition, the outcomes of the study were discouraging to the researchers (Coke, Hicks, \& Li, 2009). Students actually decreased their knowledge retention after the clinical and/or simulation experience, although not significantly. There was also no statistically significant difference in clinical performance of the students among any of the three groups. Students who participated in the combination clinical/simulation group did receive the highest scores on the clinical performance exam (although not significantly higher). The researchers indicated that replicating the study with larger samples could yield statistically significant results. Other limitations included all 
instruments were designed specifically for the study and no construct validity was established for the instruments; there were no inter-rater reliabilities established for the researchers evaluating the students; and the study was not double-blind, in that faculty may have had prior exposure to the study participants prior to evaluating them.

Clinical nursing education requires a new focus in order to adjust to changes in technology and society. Lasater and Nielsen (2009) conducted a research study that evaluated the influence of concept-based learning activities on students' clinical judgment development. The authors contend that the clinical model of assigning a student to complete total care for one or two patients fails to enhance the development of clinical judgment skills. The students may never encounter patients who allow them to develop skills necessary to treat other types of patients. For instance, a student may only care for patients who have had a myocardial infarction, and although they may become very competent in caring for this kind of patient, they would be unable to recognize or care for the needs of other types of patients (stroke patients, kidney stones, etc.). Concept based learning guides the students through a series of simulation scenarios that focus on one patient concept (such as pain, hydration status, assessment of stroke patients, or patients with diabetes). In this manner, the learning of these concepts can be scheduled, and not merely left to chance as they are in the traditional method of clinical instruction.

The quasi-experimental, mixed methods designed study had a convenience sample of 28 students including a control group (who received traditional clinical assignments) and a treatment group (who participated in concept-based simulation scenarios). Quantitative analysis revealed that students in the treatment group scored 
significantly higher in all phases of the Clinical Judgment Rubric used in the evaluation process. The activities included in the Clinical Judgment Rubric included noticing, interpreting, responding, and reflecting. The qualitative portion of this study found that students reported that they were better able to bridge theory to practice after the simulation experiences. The limitations of this study included a small sample size and the fact that the researcher was instrumental in evaluating the students with the Clinical Judgment Rubric. Despite the limitations, this research study suggests a positive influence on a students' clinical reasoning or clinical judgment development after engaging in simulation experiences.

Arundell, Ciofi, and Purcal (2005) conducted a research study that included 36 graduate, diploma midwifery students. The research question for this study was: Do midwifery students who receive simulation training arrive at assessment decisions more quickly, collect more clinical information, revisit information less often, make more inferences, and report higher confidence levels than students who receive traditional lecture? The post test design involved a control group who received a traditional lecture on labor and delivery, and an experimental group who participated in a high fidelity simulation depicting normal labor and delivery. The researchers evaluated the students' critical thinking or clinical decision-making ability during the simulation encounter. The researchers found that the experimental group collected more clinical information, asked fewer information-gathering questions, and reported higher confidence levels in taking care of patients with a normal labor and delivery. Although the sample size was very 
small (18 in each group), this study was able to show significant improvement in clinical performance after a simulation scenario.

Ellis, Lashley and Nehring (2002) conducted a research study that sought to evaluate the effectiveness of using simulation to teach critical incidents (incidents where the actions of the nurse have a direct outcome on whether the patient lives or dies) and physical assessment skills. This qualitative research study had a convenience sample size of 80 students. The researchers developed three scenarios in which the students' selfreported their level of comfort in caring for patients that needed critical intervention. The survey used terms such as very confident, confident, and not confident in describing the students' self-reporting of comfort level in taking care of a critically ill patients before and after a simulation scenario. Results of the study found that students had greater confidence in caring for and assessing patients for potential problems after participating in the simulation scenario. The researchers used their own students in the project and data were collected over a three-month time frame.

McArthur Ravert (2004) designed a mixed-methods simulation study for her group of nursing students at a four-year university. The quantitative portion of the research study had a sample size of 25 , split into a control and an experimental group. One group of nursing students was taught using a standardized written case study while the other group was given the same case study only in a high fidelity patient-care scenario. Critical thinking skills and self-efficacy (being able to perform basic nursing skills) were evaluated after the case studies/simulations. Both groups were found to have increased critical thinking skills scores (evaluated using the CCTSI and the CCTDI) and 
both groups also felt that they were more efficient in skill acquisition (evaluated through self- reporting). There was not a statistically significant increase in either confidence or critical thinking in the simulation group when compared to the control group. McArthur Ravert suggested in her discussion of the study that the small sample size was a limitation in the study. She also suggested that the CCTDI and CCTSI may not be the best test to measure critical thinking in nursing students.

Comer (2005) designed a qualitative study in which nursing students were evaluated after completing a series of 20 minute scenarios using simulation technology. Twenty nursing students were taught critical thinking skills using simulation technology, instead of a traditional lecture format. The author found that students reported that the simulator produced anxiety in the students at first, but the students then reported enjoying the experience after the scenario was completed. The students also self-reported that they understood course content better when it was presented within the simulation scenario (as opposed to a traditional lecture), and the authors observed an increase in grades (based on a prior year exam) on a course exam containing the same content as the simulation experience.

Simulation experiences involve active learning and the acquisition of psychomotor skills, as well as clinical decision-making skills. From the studies contained in this lit review (Hoadley, 2009; Clochesy, Hovancesk, \& Jamison, 2006; McArthur Ravert, 2004), it appears to be easier to evaluate skill acquisition through the use of simulation than clinical decision-making ability. Nursing researchers can use a standard test, or checklist to measure the ability of nursing students prior to and after a lecture, 
video, or skills demonstration. Clochesy et al. (2006) compared the use of two different methods to teach intravenous cannulation (placing a catheter in a vein for intravenous fluid administration). One teaching modality involved the use of a static manikin arm, and the other involved the use of a SimMan arm attached to a computer that allowed the student to simulate and see on a screen how the catheter was placed in the vein. The researchers delivered a pre and post test that evaluated the skill acquisition level of the students after either using the static arm or the computer simulation arm. Post test scores were significantly higher in the students who used the computer simulation technology.

Hoadly (2009) conducted a study in which 53 health care providers were split into two groups and taught Advanced Cardiac Life Support Skills (ACLS) using a static manikin (low fidelity) and a high fidelity computerized manikin. The author hypothesized that the participants in the experimental, high fidelity simulation group would have higher satisfaction, confidence, and test scores than the control group. The researchers used both a paper and pencil content exam and a performance exam to evaluate participants. The findings from this mixed-methods study reflected that there was no difference in satisfaction, post test performance scores, or confidence between the control and experimental group. Although the sample size was small in this study, these findings appear to contradict the similar study done by Clochesy et al. (2006). Hoadley attributed the lack of statistical findings to the limitations imposed by the use of American Heart Association (AHA) guidelines for teaching ACLS-such as limiting the number of students that can be taught at one time (six), the actual written post test (which tests knowledge), and the design of the simulation room itself. The author felt that if more 
students had been able to participate in one scenario, then greater generalizability could have occurred and the instructor could have been able to detect potential differences in the results.

Researchers Dremsa, Flagg, and Johnson (2008) conducted a study to determine the effects on cognition and critical thinking of using simulation versus a guidedinstruction CD-ROM in the teaching of effects of chemical warfare. The pre test, post test experimental design had 99 participants (all reserve and volunteer healthcare professionals) and taught the students about chemical warfare using either a CD-ROM or a simulation scenario. The researchers found that there was no significant difference in the post test scores of the subjects when it concerned lower level cognitive skills, such as memorization of facts. However, there were higher post test scores from the students who participated in simulation when it came to higher-level, critical thinking skills. The critical thinking skills identified by the researchers for testing purposes were assessment, intervention and evaluation of patient outcomes. The authors concluded that when teaching lower level cognitive skills such as knowledge or comprehension, the method of teaching is not as important as it is in the teaching of higher cognitive skills (application, analysis, and synthesis). This study lends credence to the development of a tool for the measurement of higher-order critical thinking or clinical decision-making skills in order to evaluate the effectiveness of simulation teaching methods.

The study by Clochesy et al. (2006) was part of the three-year, four-phase joint study conducted by the National League for Nursing and Laerdal Medical. Jeffries and Rizzolo (2006) were the principal participants of the final phase of the study which 
investigated whether the SimMan scenarios led to increased knowledge in a large group of nursing students. The students being studied were from 4 different colleges and the sample size (357) was significantly larger than all of the research found on simulations that is reviewed in this section. The authors chose to focus on knowledge acquisition through the scenarios. The scenario involved the care of an immediate post-operative patient. The Jeffries and Rizzolo study found, through the use of a multiple choice pre and post test, that there was more knowledge gained (use of a multiple choice pre and post test) through use of the SimMan scenario than a paper and pencil case study. Four students participated in the scenario at one time and the level of knowledge gained was the same for all 4 of the students, whether they were observing the scenario or actually participating in the patient care. Students were also much more satisfied with the scenario than with the traditional case study.

In a research study conducted in the United Kingdom, researchers found that simulation did increase the clinical performance of nursing students (Aliner, Gordon, Harwood, \& Hunt, 2006). The researchers constructed a pre and post test design and used the Objective Structured Clinical Examination (OSCE) to evaluate junior-level, diploma registered nursing students. The OSCE was originally developed to evaluate physicians. The sample size of 99 students was randomly assigned to a control group (which received only the traditional curriculum) or an experimental group (which received simulation training along with the traditional classroom curriculum). The researchers found that mean test scores improved for the experimental group of students by $14.18 \%$. The difference between the means of the control and experimental group was statistically 
significant $(p<0.001)$. The researchers also obtained data concerning stress and confidence from a 5-point Likert scale. Data analysis revealed that there was no difference in perceptions of stress and confidence between the control and experimental group. The researchers concluded that intermediate-level simulation training was very effective in nursing students. The researchers used a computerized manikin in the simulator sessions. The researcher did not clarify why they classified the simulation sessions as intermediate fidelity, unless they were comparing the experience to using living individuals in the scenario encounters.

A qualitative study completed on the use of SimMan and nursing education was done by Lasater (2007) a professor at the Oregon Health and Science University's School of Nursing. Lasater used her model of students' clinical judgment development. The four dimensions included in the model were: confidence, aptitude, skill, and experience. The author used her model to design a series of simulation experiences for her nursing students. The author's 48 nursing students rotated through a simulation laboratory for the entire semester of their junior year. Students then were asked to volunteer for a focus group that the researcher conducted after the semester was over. Only 8 of the 48 students participated in the 90 minute, videotaped focus group. The researcher (after reviewing the videotape multiple times) identified thirteen themes from the focus group comments and coded $95 \%$ of the comments into five major themes. Lasater found that students felt that the debriefing episode after the simulation experience was the key experience that led them to develop clinical judgment, and that more time should be spent by the nursing instructor in this area. Specifically the students felt that they needed more direct feedback 
during debriefing on what they did right and what they did wrong during the simulation scenario.

Research conducted by Bezanson, Brannan, and White (2008) addressed the areas of cognitive skills and confidence levels between a group involved in simulation and a group involved in a traditional classroom lecture. Content of the lecture and simulation was acute myocardial infarction and 107 students participated in the quasi-experimental pre test and post test comparison group design. The authors constructed the pre and post tests delivered to the students, which involved specific nursing content and a questionnaire concerning their confidence levels in caring for a patient with an acute myocardial infarction. The researchers found no difference in the confidence levels of the nursing students, but the post test scores found that the simulation group acquired more knowledge than did the control (lecture) group. The researchers conclude that simulation is an effective adjunct to traditional classroom lecture and more research should be done to identify best practices in simulation education.

The confidence level of students after participating in simulation scenarios was the focus of a quasi-experimental, mixed-methods design conducted by Bambini, Perkins and Washburn (2009). A sample of 112 students completed surveys regarding confidence and self -efficacy in caring for a postpartum patient and her newborn. Results indicated that students had an increase in overall self-efficacy and confidence in assessing vital signs and performing a postpartum assessment. Participants also completed a survey that indicated that they learned the importance of communicating with other healthcare providers. Student comments on the survey also indicated that they felt their psychomotor 
skills increased after the simulation. Finally, students felt that the simulation taught them the importance of prioritizing assessment skills, developing interventions, and identifying abnormal findings - all essential concepts in developing clinical judgment as defined by Alfaro-LeFevre (2004).

\section{Summary of Literature Review}

Simulation has been used in aviation and medicine for over fifty years. Research conducted in these disciplines has documented the benefit of simulation in teaching psychomotor skills, and team-management skills (Dillon, Noble, \& Kaplan, 2009; Klein et al, 2007; Ben-David, Ziv, \& Ziv, 2005;). Pharmacy students increased their ability to manage dysrhythmias in cardiac patients after participating in simulation scenarios.

Simulation use in nursing education has become more prominent in the last 10 years (Jeffries, 2008). Most of the studies conducted by nurse researchers have been qualitative in nature and focus on the students' perceptions of their simulation experience (Bambini, Perkins, \& Washburn, 2009; Comer, 2005; Dillon, Noble, \& Kaplan, 2009; Ellis, Lashley, \& Nehring, 2002; Lasater, 2007).

Research has shown that simulation correlated with increased psychomotor skill acquisition and increased acquisition of higher-level thinking skills (Clochesky et al., 2006; Dremsa et al., 2008). Research has also shown that participants had higher cognitive skills and confidence levels in caring for patients suffering from a myocardial infarction after participating in a simulation scenario over the traditional lecture format (Bezanson et al., 2008). 
The question of increasing clinical performance after a simulation encounter was posited by Coke et al., (2009) in which performance and cognitive skills were measured after students completed traditional clinical, clinical/simulation combo, and simulation only. There were no significant differences between the groups in knowledge acquisition, confidence, or clinical performance.

In the landmark study by Jeffries and Rizzolo (2006), students engaging in simulations were found to acquire increased knowledge over the students who participated in a paper and pencil case study. McArthur-Ravert conducted a similar study in 2004; however it did not indicate increased critical thinking after simulation (as measured by the CCTDI) over the traditional paper and pencil case study. Mixed results of previous studies indicate a need for more research.

A review of the literature found that more research is needed in the area of simulation in nursing education. Can simulation improve students' clinical decisionmaking skills and clinical performance?

\section{Research Methodology}

The intent of the research is to ascertain if simulation technology has an impact in the clinical decision-making ability and performance of practical nursing students. The quantitative study used an experimental differentiated treatment design with a group that was taught using a traditional paper and pencil case study and a group taught using simulation technology. Creswell (2009) stated that any time a treatment is applied to individuals, in order to ascertain if there is a change in the behavior that is not caused by chance, then quantitative research methodology should be used. An experimental design 
that utilizes differentiated treatments is especially useful in suggesting causality (Morrison, 2007). Creswell (2009) advocated the use of pre and post tests whenever participants can be randomly assigned into two groups (A and B groups) and each group is given a different treatment. Teaching method was the variable of the study. One group was taught care of a myocardial infarction patient using a traditional paper and pencil case study. The other group was taught care of a myocardial infarction patient using simulation. Using a pre and post test design allowed the researcher to measure the effect of the treatments on the outcome of the experiment.

The pre test and post tests used in the research were multiple choice exams that measure clinical decision-making through the use of items that test at the application and analysis levels. Many of the quantitative studies done in simulation technology in nursing education have used a pre test/post test design (Arundell et al., 2005; Clochesy et al., (2006); Dremsa, Flagg, \& Johnson, 2008; Jeffries \& Rizzolo, 2006; Hoadley, 2009; McArthur- Ravert, 2004). The study closely replicated the quantitative portion of the research conducted by McArthur-Ravert (2004) in which participants in the experimental group were give a simulation scenario that was identical to the paper and pencil case study given to the control group. Dremsa et al. (2008) found that participants who engaged in simulation had higher post test scores on items that measured the higher-order cognitive skills. The National Council Licensing Exam for nurses focuses on testing the graduate nurse on higher order thinking skills. A tool developed for this study that uses exam questions that only focus on application, analysis, and synthesis questions will best evaluate the critical thinking of the nurse in a practice situation. 
The independent variable in the study was teaching method (either case study or simulation technology) and the dependent variables were post test scores and a clinical performance evaluation during a simulation scenario in which both groups would participate following the post test. A true experimental design with one independent and dependent variable lends itself to the use of a one-tailed $t$-test to measure if the difference in the means of the individual pre and post test scores is significant. The clinical performance exam used the time it takes the students during their scenario to recognize and intervene (by performing cardiopulmonary resuscitation on the manikin) during a patient cardiac arrest. A $t$-test was used to calculate the difference in time to cardiopulmonary resuscitation for the case study and simulation group. A $t$-test is used when evaluating the mean differences between two or more samples (Gravetter \& Wallnau, 2005).

The research done by Coke et al. (2009) has many similarities to this research study. Students were evaluated with both a written examination and a clinical performance exam within a simulation scenario. Students were evaluated on how quickly they can recognize a cardiac arrest and intervene by performing cardiopulmonary resuscitation on SimMan. The simulator in both the Coke et al. study and this study senses when cardiopulmonary resuscitation begins and chronicles this time in the comment log that is used in the debriefing of the students after the scenario is completed. The student then reflected on their actions as they engaged in the debriefing segment of their encounter and actually appreciated how long they took to begin to save the "patient's" life. 


\section{Conclusion}

The use of simulation technology to teach nursing students has become a preferred method in the teaching of assessment skills and response to critical incidents (Hoadley, 2009). Of greater significance to nursing educators is the ability of the technology to enhance critical thinking or clinical decision-making skills, which ultimately leads to increased clinical performance. There have been few research studies involving the use of simulation in regards to nursing education (Coke et al, 2009; Gordon et al., 2005; Hoadley, 2009). Those that have focused on nursing education have been conducted by nurse educators and have involved small samples of their own students. Studies that have shown statistical differences have had larger sample sizes ( Aliner et al., 2006; Clochesy et al., 2006; Coke et al., 2009; Dremsa et al., 2008; Hicks, 1997; Kobulinsky et al., 2008; Jeffries \& Rizzolo, 2006). The one large study that was conducted involving 357 nursing students evaluated the knowledge acquisition of the participants as well as their satisfaction with the experience (Jeffries \& Rizzolo, 2006). There have been few large- scale research studies done on the subject of evaluating clinical decision-making skills in nursing students. Evaluating the effectiveness of simulation technology will allow the community of nurse educators to decide whether the expensive and time consuming simulators are better (versus the traditional, lecture, case study format) at preparing a nursing workforce able to care for the complex healthcare needs of individuals.

Section 3 will describe the project, including the research design, sample and setting, instruments used, project procedures and statistical analysis. 


\section{Section 3: Research Method}

\section{Introduction}

This section describes the methodology of this study of the clinical skills of nursing students taught using a human patient simulator and traditional paper and pencil case study. An overview of the research design and approach, setting and sample, treatment, instrumentation and materials, data collection and analysis, participant's protection, and roll of the researcher will be included in this section. This research served to answer the following questions:

1. Do nursing students taught through pedagogy using a simulator make better clinical decisions than nursing students taught through pedagogy using a paper and pencil case study?

2. Do nursing students taught through pedagogy using a simulator perform cardiopulmonary resuscitation faster than nursing students taught through pedagogy using a paper and pencil case study?

\section{Research Design and Approach}

The research questions dictated the research design of the study and the approach used in order to answer the research questions and test the null hypothesis.

The design of the study was quantitative in nature as it sought to identify if there was a difference in clinical decision-making between students who were taught using high fidelity simulation and those who were taught through a traditional paper and pencil case study. The independent variable, which was the mode of teaching how to care for a patient having a myocardial infarction, (either case study method of teaching or 
simulation scenario method of teaching), was compared to the two dependent variables of clinical performance exam times (as measured by time to cardiopulmonary resuscitation during a SimMan scenario) and clinical decision-making ability (as measured by the difference in scores from a multiple choice pre test and post test designed to measure clinical decision-making skills). A differentiated treatment experimental design was used to measure the difference in learning gains between students taught using a case study method of teaching care of the patient with a myocardial infarction and students taught the same concept using a simulation scenario. An independent, one-tailed $t$-test was used to measure if the difference in the means of the exam scores and the difference in the means of time to cardiopulmonary resuscitation between the students taught using a case study and the students taught using a simulator was significant.

\section{Experimental Method}

This quantitative study sought to test the difference in learning gained between two treatments on a sample of nursing students. Differentiated treatment experimental design was appropriate as it offers a controlled environment to isolate the effect of the independent variable (Creswell, 2009). The intent of the experiment was to test the difference in learning gains between two treatments (a high fidelity simulator versus a pencil and paper case study) of practical nursing students. This cause and effect relationship is best measured using an experimental method. Testing students' learning skills after two different teaching methods (treatments) will give more valid results concerning learning, rather than asking their opinion about teaching methods. This research sought to identify, through statistical analysis, the differences in learning that 
occur from the use of two different teaching methods. While qualitative studies have been useful in studying students and simulation technology, they did not address the question concerning quantified learning outcomes as a result of the different teaching methods.

\section{Differentiated Treatment Experimental Design}

A differentiated treatment experimental design using equivalent pre and post test measures was conducted to study the two research questions. A pre test and post test design using equivalent measures is practical for studies that seek to differentiate between two different treatments. Creswell (2009) described using a pre and post test design whenever a treatment is applied to a group and the intention of the research is to validate the likelihood that changes that occur during the research were caused by the treatment and not by chance. The experimental studies conducted on human patient simulators in nursing education have also used a pre and post test design (Arundell, Ciofi, \& Purcal, 2005; Clochesy, Hovancsek, \& Jamison, 2006; Jeffries \& Rizzolo, 2006; McArthur Ravert, 2004).

One of the intents of the research was to measure clinical decision-making ability of nursing students before and after the application of either a case study or a high fidelity simulation scenario. In order to measure this difference the students were given both a pre test and a post test concerning care of the patient having a myocardial infarction. The difference in learning gains (measured by exam scores) was analyzed using an independent, one-tailed $t$-test. Individual means on the pre tests were compared to individual means on the post test for each of the treatment groups. Clinical performance was measured by students' performance in an actual simulation scenario of a patient who 
is having a myocardial infarction, with subsequent cardiac arrest. Clinical performance was measured by how quickly the groups of students intervened when the simulated patient's heart stopped beating and the simulated patient stopped breathing. Both groups of students (case study and simulation groups) took part in the clinical performance exam. The time it took for the case study groups to provide cardiopulmonary resuscitation to the manikin was compared to the time it took the simulation groups to provide cardiopulmonary resuscitation to the manikin. A one-tailed $t$-test was used to measure the difference in time to cardiopulmonary resuscitation.

\section{Sample}

This section will describe the setting, population and sample, as well as the sampling method, and determination of sample size. This section will also describe eligibility criteria for study participants and the characteristics of the selected sample.

\section{Population}

The population consisted of all students in practical nursing programs in western and central Pennsylvania who attend one of the nursing programs that have high fidelity simulation integrated in their curriculum. The students have an anticipated graduation date during 2010 or 2011 program year. Students are eligible for graduation having met admission and curricula requirements established by the State Board of Nursing in Pennsylvania.

The State Board of Nursing in Pennsylvania establishes admission and curriculum requirements for graduation (Pennsylvania State Board of Nursing, 2008). The admission standards define several characteristics of this sample. Students admitted to practical 
nursing programs must have graduated from high school (or an equivalent general education development), have evidence of good mental and physical health (as assessed by a primary healthcare provider), have completed a basic life support (cardiopulmonary resuscitation) course, and be more than 17 years of age. Graduation requirements include fulfilling the objectives of the program in which the student was admitted, which includes at least 1,500 hours of classroom and clinical instruction.

\section{Sample}

The individuals in the sample were at the same placement in the curriculums of their respective nursing programs. The students had also had previous experience (of varying degrees) with the simulation equipment used in the research study. To reduce bias in group composition, only practical nursing programs using simulation as part of their curriculum were studied.

All the coordinators of the practical nursing programs are members of the Pennsylvania Association of Practical Nursing Administrators (PAPNA) and the researcher solicited their interest in the project at the May 2009 state meeting. The nursing coordinators from 25 of the 54 state nursing programs expressed interest in their schools to be program sites for the research. I teach in one of the state's practical nursing programs, but my program's students were not included in the study. Of the 25 schools that expressed interest, 8 of those schools are within a 75 mile radius of my home and 6 of those schools use simulation as part of their curriculum. After receiving approval from IRB to build the sampling frame, I contacted the 6 nursing program coordinators. All coordinators agreed to be included in the study, and volunteer sample size was near the 
usual 30 students per class that I had intended (to achieve the desired sample of 120 students). I randomly chose (through pick from a hat) 4 out of the 6 schools that are within a 75 mile radius of my home. One of the research schools had 2 classes running concurrently and both those classes were used for the sample. A total of 5 nursing classes were used in the study. The sample $(N=133)$ consisted of 14 males and 119 females whose average age was 32 . The students self-reported an average of 45 hours spent in the simulation lab during their education.

\section{Sampling Methods and Assignment to Treatment}

Three steps were taken to select the sample and assign selected participants to groups after obtaining IRB approval (\#05-13-10-0363561).

Step 1: From the 54 practical nursing programs in Pennsylvania, 25 programs elected to participate in the research study. For ease of travel, I chose from the 6 nursing schools that are within a 75 mile radius of my home and use the SimMan simulator as a part of their curriculum. I contacted the coordinator at each of the 6 schools to ascertain class size and whether the program coordinators still wished their schools to participate in the research

Step 2: I randomly chose 4 out of the 6 schools that are within a 75 mile radius of my home. One of the schools had two nursing classes attending concurrently, so both classes were included in the study (resulting in a total of five classes). I collected letters of participation from the coordinator of each nursing program.

Step 3: Students from the 5 participating classes chose a piece of paper, thoroughly shuffled in a bowl offered by the researcher, indicating the treatment group to 
which they were assigned, either the case study or simulation group. To insure that the groups were equal in size there was only enough pieces of paper to match the size of each of the five groups. Assignment was made through simple random selection of either blank (case study group) or marked pieces of paper (simulation group).

\section{Treatment, Instrumentation, and Materials}

Two treatments provided the conditions for examining the difference between groups, a paper and pencil case study and a simulation scenario. The dependent variables were pre and post test scores on a multiple choice exam and the speed of clinical performance during a high fidelity simulation scenario in which both groups would participate following the post test.

The simulation scenario and paper and pencil case study were developed by three basic life support and advanced life support instructors, who are also expert nurse educators. After achieving 100\% agreement in the objectives, interventions, and desired outcomes that should be included in the scenario and case study, I developed the case study and simulation scenario. I programmed the simulation software to "run" the simulation scenario.

The written case study took the student approximately ten minutes to complete.

Each student in the case study group completed the case study. Students in the case study group collaborated with each other on the case study. The simulation scenario was programmed to be completed in 10 minutes, with a 10-15 minute debriefing session after the scenario was over. Students were able to talk and collaborate during the simulation scenario. During the clinical performance exam I documented the amount of time it took 
each class' group (either Sim or case study) to provide cardiopulmonary resuscitation on the SimMan manikin. The manikin software recognized when cardiopulmonary resuscitation was started and placed that information into a debriefing log. I used the debriefing log to obtain actual cardiopulmonary resuscitation times.

I developed the pre and post test exams used in the study and they were reviewed by three nurse experts for content, congruency, and test construction (Pennsylvania State Board of Nursing, 2008). The three nursing experts categorized each question into the steps of the nursing process and rated the cognitive level of the question. Each item on the pre and post test is coded by the area of the nursing process it is measuringassessment, planning, implementation, or evaluation. Additionally, items were identified as a prioritization question if the student must rank the order of steps that should be completed. All questions tested at the application, analysis, and synthesis levels.

The nursing experts examined each question on the pre test and ensured that there was an equivalent question on the post test. The nursing experts used the categorization criteria to insure that the same number of questions addressing priority, assessment, planning, implementation, and evaluation were on both the pre and post tests. The nursing experts achieved a $96 \%$ agreement that the items on the pre and post tests were identical in terms of content, and nursing process level. Additionally, a psychometrician from Assessment Technologies Institute reviewed the pre and post tests for test construction and congruency of items between the pre and post tests. The test instruments were piloted to a group of 30 nursing students at my school over a period of 3 months. Reliability estimated using Cronbach's alpha was .80. 


\section{Data Collection}

A letter of participation was requested and received from each practical nursing program coordinator whose program was chosen as a research site. After initial participation for each school was established, the nursing coordinator for each school chose one of the schools' routine clinical/simulation days in the for data collection. On a pre-determined day I went to each nursing school, explained the research study, and passed out consent forms to the students to allow for the collection of demographic data. The researcher collected all forms--a total of 135 students consented to participate in the study, although 2 of those students were not included because their forms were incomplete. Students chose from a bowl whether they were a part of the case study or simulation scenario group.

All students then viewed a presentation on the American Heart Association's guidelines for care of the patient with a myocardial infarction. This presentation took 10 minutes to view. I read the slides to all the students. I then passed out a pre test that contained three demographic questions concerning gender, age, and experience with simulation equipment. This information was used to describe the sample. All the students then completed the pre test (see Appendix A). Then the students were divided based on random group assignment.

\section{Case Study Treatment Group}

The case study groups were directed to a classroom and given the pencil and paper case study to complete (see Appendix B). The total time to complete the case study was 10-15 minutes (average for each class). The students completed the case study as a 
group. After 15 minutes, students were given the post test (see Appendix C). The students were then directed to the simulation lab where they participated in the simulation scenario, as a team, and their clinical performance was measured by the amount of time it took them to perform CPR on the simulation manikin. The manikin software recorded the time of breaths and compressions that constitute cardiopulmonary resuscitation. The case study group then engaged in a ten minute debriefing period which I conducted. Students were told how long it took for them to provide cardiopulmonary resuscitation to the manikin during the debriefing period. The students then had a break for lunch that I provided. Students were then instructed to follow their normal class schedule after lunch.

\section{Simulation Treatment Group}

While the case study group completed the paper and pencil case study, the simulation group was directed to the simulation lab and participated in the simulation scenario. The scenario was 10 minutes long with a 10-15 minute debriefing following the scenario. The students completed the scenario as a team and then I conducted the 10-15 minute debriefing session. The simulation group then completed the post test. The students had a break for lunch which I provided. After lunch (during this time the case study group was completing the simulation scenario) the students participated in an identical simulation scenario they had participated in prior to lunch. Their clinical performance was measured by the amount of time it took them to provide cardiopulmonary resuscitation to the manikin. The manikin's computerized monitoring device documented the time to breaths and compressions for the manikin. The students then had another debriefing session after the simulation scenario. Students were told how 
long it took for them to provide cardiopulmonary resuscitation to the manikin during the debriefing period. Students were then instructed to follow their normal class schedule. The following is a graphic representation of the activities of the two treatment groups.

Table 1

Research Activities by Group

\begin{tabular}{l|c|c}
\hline & $\begin{array}{c}\text { Case study } \\
\text { group }\end{array}$ & $\begin{array}{c}\text { Simulation } \\
\text { group }\end{array}$ \\
\hline Presentation & $\mathrm{X}$ & $\mathrm{X}$ \\
Pre Test & $\mathrm{X}$ & $\mathrm{X}$ \\
Paper and pencil case study-MI & $\mathrm{X}$ & $\mathrm{X}$ \\
Simulation of MI & & $\mathrm{X}$ \\
Debriefing session & $\mathrm{X}$ & $\mathrm{X}$ \\
Post Test & $\mathrm{X}$ & $\mathrm{X}$ \\
Performance evaluation during simulation & & $\mathrm{X}$ \\
scenario & $\mathrm{X}$ & \\
Debriefing & & \\
\hline
\end{tabular}

The amount of time needed to complete the research activities was approximately 90 minutes for each nursing class. Debriefing times varied for each of the groups during the clinical performance exam, based on the individual groups' questions. Debriefing has been found to be one of the most important parts of a simulation experience. Debriefing allows students to reflect on their actions during the scenario and develop alternatives to their actions (Lasater \& Nielsen, 2009).

All pre tests, post tests, and debriefing logs were collected from the 5 nursing classes at the 4 research sites. The number and identity of students who agreed to allow their test scores and clinical performance scores to be used in the research study was 
determined from students' consent forms. All students in each class engaged in all research activities but only the exam and clinical performance scores from students who agreed to participate in the research study were used for data analysis.

\section{Data Analysis}

Data were analyzed to test the following null and alternative hypotheses:

Null Hypothesis 1: There is no difference between the clinical learning gains of students taught through pedagogy using a simulator and nursing students taught through pedagogy using a paper and pencil case study. $M \operatorname{sim}=M$ case

Alternative Hypothesis 1: There is a positive difference in the clinical learning gains of students taught through pedagogy using a simulator compared to students taught through pedagogy using a paper and pencil case study. $M \operatorname{sim}>M$ case

Null Hypothesis 2: There is no difference in time to cardiopulmonary resuscitation of nursing students taught through pedagogy using a simulator and nursing students taught through pedagogy using a paper and pencil case study. $M \operatorname{sim}=M$ case

Alternative Hypothesis 2: There is a negative difference in time to cardiopulmonary resuscitation of nursing students taught through pedagogy using a simulator and nursing students taught using a paper and pencil. $M \operatorname{sim}<M$ case

The pre and post test exams were scored based on a percentage scale (from 0$100 \%$ ). Exams were scored based on the percentage (out of 100) of items the student got correct.

The post test scores were subtracted from the pre test scores for each student participant and the difference between the pre and post test for each student participant 
were measured. A non-significant Levene's test $F=.827, p>.001$, indicated variances between the two treatment groups were equal and so homogeneity was assumed. The mean difference of all the individual pre tests and post tests as measured using an independent, one-tailed $t$-test (Gravetter \& Wallnau, 2005).

The cardiopulmonary resuscitation times or clinical performance times from the clinical simulation exams were compared (data were normally distributed). A nonsignificant Levene's test, $F=.66 .851, p>.001$, indicated variances between the two treatment groups were equal and so homogeneity was assumed. An independent samples $t$-test was conducted to determine if the simulation groups responded more quickly during the code blue procedure by performing cardiopulmonary resuscitation faster than the case study groups. Data were normally distributed for both dependent variables.

The statistical analysis used a strategy that reduces Type II statistical errors at the expense of making an increased number of Type I statistical errors. The strategy was to conduct independent $t$-tests significant at $p \leq=0.20$ for the difference in exam scores and the mean time to cardiopulmonary resuscitation.

\section{Participants' Protection}

To insure ethical standards of research were being upheld, all methods of the study were approved by the Walden University IRB, approval number 05-13-100363561.

On the consent to collect demographics form (Appendix D) students indicated their agreement to have their demographic data collected. Students participated in research activities as part of their normal educational class. Students were assured 
confidentiality in their participation. Students placed their name and treatment group on their pre test form and their post test form. The students were evaluated as a group during the clinical performance exam. All data were kept locked in a file cabinet in the nursing coordinator's office (in the participating school) until I left the research site. Data were then placed in a locked file cabinet in my home.

A simulation experience can be an emotional event for some students. The debriefing session after the simulation experience was useful in discussing any psychological factors or feelings the students may have had during the encounter. The simulator was programmed to respond favorably to the students' basic life support measures immediately upon initiation of CPR. Students' actions did not result in the demise of the manikin, but the manikin was brought back to life through the efforts of the students. Objectives of the simulation encounter were to allow the students to recognize a cardiac arrest situation and intervene by performing basic life support.

The confidentiality of the students was protected by the researcher. No member of the faculty of their nursing school knew who consented to participate in the study, and allowed their demographic data to be collected. I was the only person who could match student names with exam results. Students could have changed their mind about consent to collect demographics at any time during the research study and I would have removed those students' data and place them in a separate file, which I would have kept for five years. No students contacted me to withdraw consent for use of their exam or demographic information. 


\section{Role of the Researcher}

I selected the participating schools that were the sites for the research study.

Students from my own nursing program were not involved in the research. I described the research day activities and obtained consent from students to collect demographic data. I

randomly assigned students to treatment groups and conducted all the research day activities and input the raw data into a secure database. My committee methodologist validated my data analysis procedures and the results from the study. 


\section{Section 4: Data Analysis}

\section{Introduction}

This section describes the data analysis process used to answer research questions, interprets the findings as they relate to each research question, and summarizes statistical findings. The difference between individual scores for pre tests and post tests (measuring ability to care for a patient having a myocardial infarction), as well as time to cardiopulmonary resuscitation, were used to complete the data analysis process. Statistical analysis supported rejecting the null hypothesis for both research questions: there was a positive difference in clinical learning gains and a negative difference in time to cardiopulmonary resuscitation for the student participants in the simulation group, as compared to student participants in the case study group.

\section{Research Questions}

Data were analyzed to test the following null and alternative hypotheses:

Null Hypothesis 1: There is no difference between the clinical learning gains of students taught through pedagogy using a simulator and nursing students taught through pedagogy using a paper and pencil case study. $M \operatorname{sim}=M$ case

Alternative Hypothesis 1: There is a positive difference in the clinical learning gains of students taught through pedagogy using a simulator compared to students taught through pedagogy using a paper and pencil case study. $M \operatorname{sim}>M$ case

Null Hypothesis 2: There is no difference in time to cardiopulmonary resuscitation of nursing students taught through pedagogy using a simulator and nursing students taught through pedagogy using a paper and pencil case study. $M u$ sim $=M$ case 
Alternative Hypothesis 2: There is a negative difference in time to cardiopulmonary resuscitation of nursing students taught through pedagogy using a simulator and nursing students taught using a paper and pencil. $M \operatorname{sim}<M$ case

\section{Data Analysis}

Scores for the 133 individual pre test- post test clinical learning- and time to cardiopulmonary resuscitation were entered into the statistical software package SPSS 16.0. The average age of participants was $32 ; 12 \%$ of the participants were male and $88 \%$ were female. The average number of self-reported previous simulation experience hours was 45. Individual scores were entered into the data editor. Descriptive statistics were computed for the sample as well as an independent measures $t$-test (for the post test scores and time to cardiopulmonary resuscitation scores).Findings supported rejection of the null hypothesis for both research questions. The following describes how statistical findings relate to research questions.

\section{Research Question 1: Interpretation of Findings}

For statistical purposes, the randomly assigned treatment groups were labeled as 1 (simulation group) and 2 (case study group). Individual scores of all 133 students in the two groups on the pre tests and post tests were entered into SPSS as the dependent variables and the treatment group was entered as the independent variable

There was no statistical difference in pre test scores from group 1 or group 2. Students did equally well on the pre test whether they were in the simulation or case study group. Students had viewed a short presentation on American Heart Association guidelines for care of the patient with a myocardial infarction prior to being randomly 
assigned to a treatment group. All students in all classes had had previous lecture content on care of the patient with a myocardial infarction as part of their nursing classes, in addition to the presentation on the research day. Descriptive statistics on the sample were formulated by the statistics program and are included in Table 2.

\section{Table 2}

Pre and Post Test Percentage Scores

$\begin{array}{cccccc} & \text { Treatment } & n & \text { Mean } & \text { SD } & S E \\ \text { Pre- } & 1 & 66 & 48.8 & 13.2 & 1.63 \\ \text { test } & 2 & 67 & 49.6 & 14.5 & 1.76 \\ \text { Post- } & 1 & 66 & 69.7 & 12.2 & 1.50 \\ \text { test } & 2 & 67 & 61.6 & 13.77 & 1.69\end{array}$

The mean score on the pre test was $49 \%$ for the simulation group and $50 \%$ for the case study group. Low scores can be attributed to the complexity of the questions contained on the pre and post test. All items on the exam tested for comprehension of care of the patient with a myocardial infarction at application, synthesis, and analysis levels. Following is an example test item from the pre test (see Appendix B):

A client having shortness of breath and chest pain during a ST segment elevated myocardial infarction would benefit most from the administration of
a. oxygen and morphine
b. aspirin and Plavix
c. nitroglycerine and aspirin
d. heparin and oxygen

In order for participants to answer correctly, they would have needed to choose from the distracters the group of medications that would best benefit the patient with chest pain 
and shortness of breath. All the medications indicated in the distracters might eventually be given to an individual experiencing a myocardial infarction.

There was a 20-point gain for individuals in the simulation groups and a 12-point gain for individuals in the case study group on the post test exam. The results suggest learning occurred in both the treatment groups however the learning difference was greater in the simulation group. A one-tailed independent-samples $t$-test was performed on the data

The simulation group had greater learning gains $(m=8, S D=13.7)$ than the case study group $(m=-.7, S D=13.2)$. The difference between pre and post test treatment exam scores was significant $(t=3.56, p<.001)$ (Gravetter \& Wallnau, 2005). Students in the simulation group did significantly better on the post test than did the case study group.

The results support the rejection of Research Question 1's null hypothesis and acceptance of the alternative hypothesis. There was a statistically significant learning gain for students taught through pedagogy using a simulator compared to students taught through pedagogy using a paper and pencil case study ( $m \operatorname{sim}>m$ case $)$.

\section{Research Question 2: Interpretation of Findings}

Clinical performance was measured by the amount of time it took each group to provide cardiopulmonary resuscitation $(\mathrm{CPR})$ to the manikin during a cardiac arrest. Individuals were assigned the amount of time that it took their group (either simulation or case study) to administer CPR to the manikin. The average time for the 5 simulation groups to provide CPR was 32 seconds. The average time for the 5 case study groups to provide CPR was 62 seconds. An independent-samples $t$ - test was performed by SPSS. 
The simulation groups performed CPR quicker ( $m=32$ seconds, $S D=12.8)$ than the case study groups ( $m=62$ seconds, $S D=22.2)$. This difference was significant, $t=$ -9.62, $p<.001$. (Gravetter \& Wallnau, 2005). Students in the simulation groups were able to provide CPR 30 seconds faster, or almost twice as quickly, than the case study groups. The results support the rejection of Research Question 2's null hypothesis and accept the alternative hypothesis. There is a negative difference in time to cardiopulmonary resuscitation of nursing students taught through pedagogy using a simulator and nursing students taught using a paper and pencil ( $m \operatorname{sim}<m$ case $)$.

\section{Summary}

The results of the data analysis indicated that null hypotheses for both research questions should be rejected. The positive learning gains of simulation groups on the post-test exam were statistically significant at the $99.9 \%$ confidence level. Additionally, students in simulation groups had a statistically significant negative decrease in time (compared to case study group) to CPR. The American Heart Association statistics state that for every minute that basic life support is delayed, the patient's chance of survival decreases by $10 \%$ (American Heart Association, 2005). This suggests using simulation as a teaching method may increase the ability of nurses to provide cardiopulmonary resuscitation more quickly and effectively than nurses who are taught using case study method. 
Section 5: Conclusion and Recommendations for Further Study

\section{Overview}

This section will provide an overview of the research study, including interpretation of findings and how they relate to the theoretical framework of the study and previous research conducted in the field. Implications for social change, recommendations for action, and recommendations for further study will also be covered in this section.

This research was conducted to evaluate the use of simulation technology in the preparation of student nurses. Nursing programs have routinely used simulation technology, although there is a gap in the literature regarding the value in using this complex teaching method. The community of nursing education needs research studies that validate the use of the expensive, labor-intensive teaching method. This research validated the use of simulation technology in teaching clinical decision-making to practical nursing students in four program sites in western and central Pennsylvania.

The research project was conducted over 3 days in May, 2010. Consent to participate was given by all students involved in the research project $(N=135)$. Students received a short presentation on care of the patient with a myocardial infarction. Participants were randomly assigned to 1 of 2 treatment groups-simulation or case studyby pick from a thoroughly shuffled bowl. A pre test measuring baseline knowledge of care of the patient with a myocardial infarction was given. The exam tested students at the application, synthesis, and analysis level. Students then completed either a simulation scenario or a paper and pencil case study, and a post test was administered to the 
students. After the post test, all students completed a simulation scenario that measured the time to CPR by students in each treatment group.

Data from 133 participants were used in data analysis (two individuals had incomplete data and were excluded from the study). An independent samples one-tailed $t$ test compared the mean on the post test scores to the mean on the pre test exam. Students in the collective simulation group had a statistically significant positive learning gain $(p<$ 0.001) over the collective case study group.

Clinical performance times (as measured by time to CPR on the manikin) were analyzed by an independent samples one-tailed $t$-test. Students in the simulation groups had a statistically significant $(p<0.001)$ decrease in time to CPR over the case study groups. Simulation groups were able to begin CPR within 30 seconds of finding the patient unresponsive.

This research validates the use of simulation technology as a method for teaching clinical decision-making. Teaching with HPS technology resulted in greater student learning gains when compared to learning gains of students taught using paper and pencil case study as a teaching method.

\section{Interpretation of Findings}

Findings of this research add to the body of literature on the subject of using simulation technology as a teaching method for clinical decision-making in nursing education. The large community of practice of nursing educators has advocated for the use of simulation as a method for teaching clinical decision-making skills. Simulation is widely used in nursing education without a large body of evidence to support its use 
(Jeffries, 2008). The maintenance, training of staff, and upgrading of the computer software is expensive and extensive and nurse educators need a large body of evidence to support the use of simulation.

The pre test and post test exams used in this research study tested the student at the application, analysis, and synthesis levels of cognition, very much like the National Council of State Boards of Nursing (NCSBN) licensing exam (Coke, Hicks, \& Li, 2009). The exams contained multiple choice and prioritization questions. The simulation groups had greater positive learning gains on the post test exam. These students had undergone a simulation scenario prior to the exam that allowed them to apply theoretical knowledge to an actual patient situation. Student participants in the case study groups engaged in a paper and pencil case study prior to their post test exam. John Dewey (1997) theorized that greater learning takes place when students are able to interact with their environment. Problems and conflicts inherent in a situation provoke thought and reflection from students. As students repeat the encounters, they are able to adapt to and solve problems. I believe this is why the student participants in the simulation groups were able to perform better on both the post test exam and the clinical performance exam. Students already had an "experience" to draw upon and were able to problem solve and react more quickly to problems that closely mimicked the conflicts they had encountered in their previous simulation experience.

\section{Research Findings and Theoretical Framework}

Patricia Benner (1984) was the guiding theorist for this research study. Benner postulated that nursing expertise is situational and contained within a patient care 
experience. Nurses become experts at their profession by experiencing the same type of patient encounter over and over again. The nurse can draw on the experience of a variety of differing situations to formulate a plan of care for a patient that will result in the best possible outcome of that particular patient situation.

Benner (1984) posited that only through years of experience can a nurse become an expert. Simulation technology allows nurse educators to program patient encounters that allow the student to develop essential critical thinking or clinical reasoning skills without risking patient safety (McArthur Ravert, 2004). Nurse educators can simulate patient encounters that foster the type of reasoning that students would normally have to wait to experience in a clinical environment with real patients. In this research study the simulation groups performed CPR more quickly than the case study groups. The negative difference in time to CPR could increase a patient's survival rate by $5 \%$ (American Heart Association, 2005). Students in the simulation groups had already "practiced" caring for a patient with a cardiac arrest, therefore they were able to intervene more quickly than the case study groups did. Although the case study groups encountered the same patient situation in the paper and pencil case study, they did not have the same level of applied learning that the simulation groups experienced.

\section{Research Findings and Previous Nursing Simulation Research}

Many nursing research studies on simulation have also used a pre test and post test design (Arundell, Ciofi, \& Purcal, 2005; Clochesy, Hovancesk, \& Jamison, 2006; Jeffries \& Rizzolo, 2006: McArthur Ravert, 2004). The design of this research study closely replicates the quantitative portion of McArthur Raverts' (2004) study of 
baccalaureate students. A sample size of 25 limited the generalizability of the research findings, which found that both the case study and simulation groups increased their critical thinking scores. Jeffries and Rizzolo (2006) conducted a landmark study in cooperation with Laerdal, the manufacturer of the largest line of simulation equipment marketed to nursing schools. The researchers found that students in the simulation group increased their knowledge acquisition over the students who participated in the case study.

A study conducted in the United Kingdom found that simulation led to an increase in clinical performance of nursing students (Aliner, Gordon, Harwood, \& Hunt, 2006). The researchers used a pre and post test design and a clinical judgment rubric to evaluate simulation training in diploma registered nursing students. The sample size of 99 students lent statistically significant results. Students in the simulation group increased their learning by $14 \%$ over the students who received traditional lecture.

My research study examined the ability of practical nursing students to provide basic life support to a patient who had come to a hospital complaining of chest pain. The simulated patient subsequently had a heart attack and a cardiac arrest. As of this date no published research has been conducted with practical nursing students and simulation. Although practical nurses would not engage in advanced cardiac life support, they are expected to be able to provide fundamental basic life support, including CPR and automatic defibrillator training. Clontz, Dongilli, Shatzer, and Tasota (2010) found that the first 5 minutes that a patient has a cardiac arrest are the most critical to the patient's survival. As the bedside caregiver, practical nurses are sometimes the first individuals to 
find arrest victims, especially in long-term care facilities. More research should be done to examine the ability of all nurses to provide the first 5 minutes of care needed by victims of cardiac and respiratory arrest.

\section{Implications for Social Change}

The predominant change that could occur from the research findings revolves around the accepted use of simulation to train nursing students. I feel that the extensive amount of money my own school has spent on simulation training, manikins, and software has been justified by my research findings. I now have more confidence in advocating the large amount of simulation training that my school currently gives student nurses. These findings suggest simulation training does assist the student to develop the critical thinking skills necessary in the fast-paced, technologically advanced, healthcare arena. However, this is only one study and more studies revolving around simulation and the acquisition of critical thinking skills need to be done.

Traditional nursing education revolves around faculty assigning students to 1 or 2 patients each clinical day. The amount of clinical learning that occurs for the student each day is left to chance; the student may never encounter a patient who allows them to develop some of the critical thinking skills they will need to provide safe care to patients after they graduate.

Lasater (2007) has advocated for the use of concept-based learning in lieu of traditional clinical assignments. She attests that nursing faculty should structure certain patient encounters (easily accomplished with simulation) that will allow the student to develop clinical decision-making skills. Cardiac arrest (also known as code blue) training 
is one area that Lasater believes should be created for the student to experience, much like the training that occurred during my research study.

The net effect for a change in nursing education is better patient outcomes. Nursing students who are more equipped to respond to critical incidents will become more competent nurses in caring for patients, increasing survival rates for patients who have life-threatening illnesses.

\section{Recommendations for Action}

Nursing faculty should use this study's findings to advocate for a change in the direction of nursing education. Educators should move away from the typical clinical day, where they leave the bulk of the learning that is done by students to chance: if the student has a challenging patient with more opportunities for learning then they will develop good clinical reasoning skills. However, if the student does not have certain learning opportunities, he or she may never develop the skill sets necessary to care for society. Simulation affords nursing faculty the opportunity to structure learning opportunities for students that they may never encounter in a traditional clinical model. Faculty need to institute more simulated learning experiences into the curriculum. Concept-based learning (through the use of simulation) should be the direction for future nursing education.

\section{Recommendations for Further Study}

This research study should be replicated with nursing students of differing educational levels (registered nurses and practical nurses) and other healthcare providers. The research itself used a simple simulation scenario that other researchers could easily 
replicate. The entire data collection process for a nursing class of 40 students ( 1 nursing class) only took 90 minutes to complete. Future research that replicates findings in this study would validate (or invalidate) the use of simulation technology in nursing education.

Additionally, research should be done that evaluates if the teaching of critical incidents using simulation technology results in positive patient outcomes. A longitudinal study of nursing students who have received critical incident simulation training in nursing school is needed. Following these students through their nursing career and evaluating how simulation has impacted their patients' outcomes would lend further support for the use of simulation training in nursing education.

\section{Conclusion}

The original problem that was the driving force for this research was the question of whether simulation technology is worth the time, effort, and expense that the technology requires. The review of the literature resulted in a small number of quantitative studies that addressed the value in the use of simulation in nursing education. I believe that the findings of this study will make a substantial contribution to the small body of quantitative research that has been conducted involving simulation technology and nursing education. The statistically significant findings of this research validate the use of simulation technology in nursing education. There is now more evidence that simulation technology is worth the investment of time and money required for its use. 
References

Alfaro-Lefevre, R (2004). Critical thinking and clinical judgment: A practical approach. St. Louis MO, Elsevier.

Aliner, G., Gordon, R., Harwood, C., \& Hunt, B. (2006). Effectiveness of intermediate fidelity simulation training technology in undergraduate nursing education. Journal of Advanced Nursing, 54(3), 359-369.

American Heart Association, (2005). Guidelines for care of the patient with a myocardial infarction. Retrieved from aha.org on December $12^{\text {th }}, 2009$.

Arundell, F., Ciofi, J. \& Purcal, N. (2005). A pilot study to investigate the effect of a simulation strategy on the clinical decision making of midwifery students. Journal of Nursing Education, 44(3), 139-148.

Bambini, D., Perkins, R., \& Washburn, J. (2009). Outcomes of clinical simulation for novice nursing students: Communication, confidence, clinical judgment. Nursing Education Perspectives, 30(2), 79-83.

Ben-David, S.,Ziv, A., \& Ziv, M. (2005). Simulation based medical education: An opportunity to learn from errors. Medical Teacher, 27(3), 193-199.

Benner, P. (1984). From novice to expert: Excellence and power in clinical nursing practice. Menlo Park, CA. Addison-Wesley.

Bezanson, J., \& Brannan, J. (2009). Simulator effects on cognitive skills and confidence levels. Journal of Nursing Education, 47(11), 495-501 
Bond, W., \& Spillane, L. (2002). The use of simulation for emergency medicine resident assessment. Academic Emergency Medicine, 9(11), 1295-1299.

Castillo, S. (2006). Strategies, techniques, and approaches to thinking: Critical thinking cases in nursing. St. Louis, MO. Elsevier.

Clochesy, J., Hovancsek, M., \& Jamison, R. (2006). A pilot study assessing simulation using two simulation methods for teaching intravenous cannulation. INACSL Online Journal, INACSL. Retrieved June $12^{\text {th }}, 2007$ from INACSL database.

Clontz, A., Dongilli, T., Shatzer, M., \& Tasota, F. (2010). What's the 411 on the first five? Nursing 2010, 40(4), 55-57.

Coke, L., Hicks, F., \& Li, S. (2009). The effect of high-fidelity simulation on nursing students' knowledge and performance: A pilot study. National Council State Boards of Nursing, Volume 40. NCSBN online.

Comer, S.K. (2005). Patient care simulations: Role playing to enhance clinical understanding. Nursing Education Perspectives, 26(6), 357-361.

Creswell, J. (2009). Research Design: Qualitative, quantitative and mixed methods approaches. Thousand Oaks, CA. Sage Publications.

Dempsey, L., \& Stewart, S. (2005). A longitudinal study of baccalaureate nursing students' critical thinking dispositions. Journal of Nursing Education, 44(2), $81-85$

Dewey, J. (1938/1997). Experience and education. McMillan.

Dillon, P., Kaplan, L., \& Noble, K. (2009). Simulation as a means to foster collaborative interdisciplinary education. Nursing Education Perspectives, 30(3), 87-91. 
Dremsa, Tl, Flagg, A., \& Dremsa, T. (2008). Effects of using human patient simulator (HPS) versus a CD-ROM on cognition and critical thinking. Medical Education Online.

Dreyfus, S. \& Dreyfus, H. (1980), A Five-Stage Model of the Mental Activities Involved in Directed Skill Acquisition, Storming Media, $\underline{\text { http://www.stormingmedia.us }}$

Ellis, W.E., Lashley, F.R., \& Nehring, W.M. (2002). Critical incident nursing management: Using human patient simulators. Nursing Education Perspectives $2(3), 128-132$.

Gaba, D. (2007). Out of this nettle, danger, we pluck this flower, safety: Healthcare vs. aviation and other high hazard industries. Journal of the Society for Simulation in Healthcare, 2(4), 213-217.

Giddens, J., \& Gloeckner, G. (2005). The relationship of critical thinking to performance on the NCLEX-RN. Journal of Nursing Education, 44(2), 85-90.

Gordon, D., Issenberg, S., McGaghie, W., Petrusa, E., \& Scalese, R. (2005). Features and uses of high-fidelity medical simulations that lead to effective learning: A BEME systematic review. Medical Teacher 26(1), 10-28.

Gravetter, F. \& Wallnau, L. (2005). Essentials of statistics for the behavioral sciences, ( $5^{\text {th }}$ ed). Belmont, CA. Wadsworth/Thompson Learning.

Hadley, R. \& Mitchell, L. (1995). Counseling research and program evaluation. Pacific Grove, CA. Brooks/Cole Publishing Co. 
Hicks, F. (1997). Critical thinking abilities and clinical decision-making consistency among critical care nurses. Dissertation Abstracts International, 58(04), 1801. (UMI No. AAT9728482).

Hoadley, T. (2009). Learning advanced cardiac life support: A comparison study of the effects of low- and high fidelity simulation. Nursing Education Perspectives, $30(2), 91-95$.

Issenbergt, S. \& Scalese, R. (2008). Simulation in health care education. Perspectives in Biology and Medicine, 51(1), 31-46.

Jeffries, P. (2008). Getting in STEP with simulations. Nursing Education Perspectives, 29(2), 70-73.

Jeffries, P., Rizzolo, M.A. (2006). Summary Report-Project title: Designing and implementing models for the innovative use of simulation to teach nursing care of ill adults and children: a national, multi-site, multi-method study. National League for Nursing and Laerdal. Retrieved March 20 ${ }^{\text {th }}, 2007$ from National League for Nursing database.

Klein, C., Parker, C., Salas, E., Stagl, K., \& Van Eynde, D. (2007). Returning to flight: Simulation-based training for the US National Aeronautics and Space Administration's space shuttle mission management team. International Journal of Training and Development, 11(2), 132-138.

Kobulinsky, L., McKaveney, T., \& Seybert, A. (2008). Human patient simulation in a pharmacotherapy course. American Journal of Pharmaceutical Education, 72(2), 1-6. 
Lasater, K. (2007). High-fidelity simulation and the development of clinical judgment: Students’ Experiences. Journal of Nursing Education 46 (6), 30-38.

Lasater, K. \&Nielsen, A. (2009). The influence of concept-based learning activities on students' clinical judgment development. Journal of Nursing Education, 48(9), $441-447$

Martin, C. (2002). The theory of critical thinking in nursing. Nursing Education Perspectives, 23, 243-247.

McArthur Ravert, P.K. (2004). Use of a human patient simulator with undergraduate nursing students: A prototype evaluation of critical thinking and self efficacy. An unpublished doctoral dissertation, College of Nursing, University of Utah.

Morgan, P., \& Pardue, K. (2008). Insights into working with the millennial generation. Nursing Education Perspectives 29(2), 74-79.

Morrison, M. (2007). What do we mean by educational research? In A. Briggs \& M. Coleman (Ed). Research Methods in Educational Leadership and Management $\left(2^{\text {nd }}\right.$ ed), (pp. 13-36). Thousand Oaks, CA: SAGE Publications Ltd.

MSNBC, "N.Y. Jet Crash Called 'Miracle on the Hudson"" http://www.msnbc.msn Murray, D., Boulet, J., Ziv, A., Woodhouse, J., Kras, J., \& McAllister, J. (2002). An acute care skills evaluation for graduating medical students: A pilot study using clinical simulation. Medical Education, 36, 833-841.

Pardue, K. \& Morgan, P. (2008). Insights into working with the millennial generation. Nursing Education Perspectives, 29(2), 75-79. 
Pennsylvania State Board of Nursing, (2008).Code: Title 49 Bureau of Occupational Affairs, Harrisburg, PA.

Riddell, T. (2007). Critical assumptions: Thinking critically about critical thinking. Journal of Nursing Education 46(3), 121-127.

Schon, D. A. (1983). Educating the reflective practitioner. San Francisco: Jossey-Bass.

Schon, D. (1983). The reflective practitioner: How professionals think in action. Basic Books, Inc.,USA.

Schott-Baer, D., \& Touriniemi, P. (2008). Implementing a high-fidelity simulation program in a community college setting. Nursing Education Perspectives, 29(2), 105-109.

Sergiovanni, T. (2005). Strengthening the heartbeat: Leading and learning together in schools. San Fransisco, CA. Jossey-Bass,

Simones, J. (2008). Creating a home care simulation laboratory. Nursing Education, 47(3), 131-133.

Tagliareni, M. E. (2009). Beyond the realities of current practice: Preparing students to provide safe and effective care. Nursing Education Perspectives, 30(2), 69. 
Appendix A: Pre test: Care of the Patient Experiencing a Myocardial Infarction

Demographics information

1. What is your sex? Male

2. What is your age?

3. Approximately how many hours of simulation experience have you had in your course of study?

Please select the best possible answer

1. A client has the following EKG abnormalities. Which of the following would indicate that the client has had a myocardial infarction?
a. bundle branch block
b. pacemaker spike
c. ST segment elevation
d. Tall $\mathrm{T}$ waves

2. A nurse observes a client in a long-term care facility lying on the floor with agonal respirations. The client has a faint but steady pulse. What is the nurse's next course of action?
a. Begin CPR
b. Administer two rescue breaths every five seconds.
c. Call an ambulance
d. Call a code.

3. A nurse is giving chest compressions during a code blue. Which of the following demonstrates that the nurse is performing compressions correctly?
a. The client's blood pressure is $100 / 50$
b. The client has a palpable pulse
c. The nurse compresses the sternum $1 / 2$ inch with each compression. 
d. The client is able to resume spontaneous respirations.

4. A fifty-five year old woman presents to the ER with shortness of breath, nausea, vomiting and back pain that began approximately six hours ago. Which symptoms can be indicative of a heart attack in a female? Choose all that apply.
a. nausea
b. vomiting
c. back pain
d. shortness of breath

5. A client experiences chest tightness and pressure after shoveling snow. What action should be taken first to treat this condition?
a. Check vital signs
b. Encourage the client to rest
c. Call 911
d. Establish IV access

6. A client has been given a thrombolytic for a myocardial infarction with ST segment elevation. Which of the following symptoms should the nurse alert the client to report immediately?
a. chest pain
b. headache
c. shortness of breath
d. bleeding

7. A client having shortness of breath and chest pain during a ST segment elevated myocardial infarction would benefit most from the administration of

e. oxygen and morphine

f. aspirin and Plavix

g. nitroglycerine and aspirin

h. heparin and oxygen 
8. A newly admitted ER client complaining of chest pain needs the following tasks completed:

administration of oxygen

EKG performed

blood drawn for serum cardiac markers

aspirin given

SL nitroglycerin administered

History completed

Rank the order in which the tasks should be performed.

9. A nurse is reviewing code records from the previous month. Which one of the following is considered an acceptable response times from when the patient was found unresponsive and chest compressions began?
a. sixty seconds
b. three seconds
c. thirty seconds
d. ten seconds

10. A nurse encounters a client in the bathroom outside the ER complaining of chest discomfort. What is the nurse's next course of action?
a. Call for transport to the catheterization lab
b. Escort the client to a bed in the emergency room
c. Tell the client to sit in the waiting room while you check with the ER physician.

d. Escort the client to registration and then transfer him by wheelchair to the ER.

11. A client diagnosed with angina is prescribed both nitroglycerine and morphine for pain. For which of the following situations should the client be given Morphine?
a. When oxygen fails to relieve the client's pain.
b. When the client first experiences chest pain.
c. When the client's pain is unrelieved by nitroglycerine .
d. When the client's pain is accompanied by dyspnea. 
Appendix B: Case Study: Care of the Patient Experiencing a Myocardial Infarction

Your reference \#

Treatment

Jeff Smith arrived at the Emergency Department complaining of sharp chest pain after cutting grass in his back yard. The pain began approximately 30 minutes before his arrival at the ED. He is 45 years old and has no known medical history. He is 74 inches tall and weighs $238 \#$. Initial assessment reveals an alert, oriented male patient with a temperature of $37.2 \square$, heart rate of 118 , respiratory rate of 26 and SpO2 of $91 \%$. You note that he has weak peripheral and central pulses. He is diaphoretic and pale in color. He repeatedly states, "My chest hurts."

Based on these findings, what would your next course of action be?

What is the first diagnostic test that should be completed on Mr. Smith? What other diagnostic tests are indicated?

While awaiting diagnostic results, you perform a brief focused assessment. What is your primary concern and what are the early treatments options for this?

The EKG results are as follows:
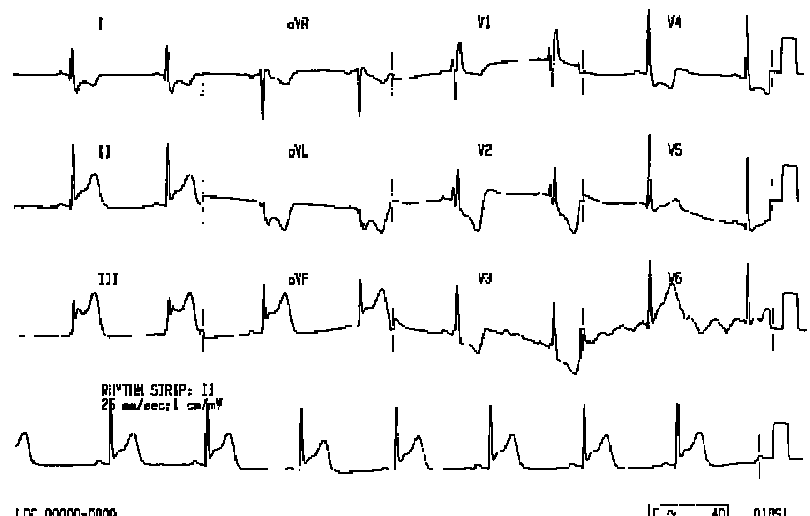

You notice ST elevation in the inferior leads: II, III, \& aVF. You also notice ST depression in the anterior leads. What does this indicate? 
Would Mr. Smith be a candidate for Fibrinolytics or PCI at this time, why or why not?

As you await further diagnostic studies, the patient reports increased pain in his left chest. You perform a rapid assessment and discover his blood pressure is now 82/40. What action is indicated at this time?

Are there any medications that should be given to Mr. Smith to help control the pain? Are there any medications that are contraindicated and why are they contraindicated?

What are the specific treatment options available to Mr. Smith and what teaching should be provided to prepare for these options?

As you are providing patient teaching on fibrinolytics, what are some of the potential complications that Mr. Smith should be aware of?

In reviewing this education, Mr. Smith begins complaining of increased chest pressure down into his left arm and up into his jaw. As he is trying to talk, he becomes unresponsive and the monitor reveals he is in Ventricular Fibrillation. What is your next course of action?

What guides this course of action?

After 35 minutes of resuscitative efforts, there is still no response and the physician orders resuscitation to be stopped. What is your next course of action? 
Appendix C: Post Test: Care of the Patient Experiencing a Myocardial Infarction

Your reference \#

Treatment

Post test: Choose the one best answer

1. A nurse has admitted a client with complaints of chest pain over the last two hours. There are no clear changes in the 12 lead EKG. Which laboratory test or tests are indicative of a myocardial infarction. Choose all that apply.

1. Tropinin of 1.9

2. Potassium of 5.2

3. $\mathrm{CPK}$ of 545 with $\mathrm{MB}$ of $5 \%$

4. WBC of 11.4

5. Dig level of 2.0

2. A nurse enters an adult client's room and the client does not respond. Put the nurse's actions in the order of priority.

1. Call for someone to announce a code blue.

2. Open the airway.

3. Shake the client's shoulders and ask, "Are you ok?"

4. Take the ambu bag from the head of the bed and give two breaths.

3. A nurse who is documenting during a code blue on an adult client observes an unlicensed assistive personnel doing CPR. The nurse interprets the UAP is performing CPR correctly after noticing that the UAP delivers at least

1.90 compressions per minute

2. 12 compressions in 30 seconds

3. 100 compressions per minute

4. One breath for every 15 compressions

4. If a client experiencing a myocardial infarction is typical of most individuals experiencing chest pain, what part of the body would the client report the pain is radiating to?

1. Arm

2. Groin

3. Abdomen

4. jaw 
5. A nurse administers sublingual nitroglycerin to a client in the ER complaining of severe chest pain. The client fails to alert the nurse that he has taken Viagra the day before. Which of the following symptoms should the nurse expect?
a. The client develops dyspneia.
b. The client develops atrial fibrillation.
c. The client develops hypotension.
d. The client's develops high blood pressure.

6. Which of the following is the correct method to teach a client how to administer nitroglycerine?

a. Take one tablet every two minutes, if the pain is unrelieved until the pain stops.

b. Take one tablet and rest until the pain stops.

c. Take two tablets every three minutes for a total of three doses.

d. Take one tablet every five minutes, if the pain is unrelieved for a total of three doses.

7. A client with acute ST segment elevation should be rapidly assessed for which of the following treatment options?
a. Morphine
b. Thrombolytics
c. Echocardiogram
d. IV Nitroglycerin

8. A client has been assigned a bed in the ER. Which of the following actions should occur within ten minutes of their hospitalization? Choose all that apply.
a. Chest $x$ ray
b. EKG
c. Oxygen at 4-6 L n/c
d. IV access
e. Obtain serum cardiac enzymes

9. A client experiences all of the following symptoms. Which of the following is considered an adverse effect of thrombolytic therapy?
a. Hypotension
b. Vomiting
c. Bleeding
d. Diarrhea 
10. A physician stops a code blue after 40 minutes. Which of the following should the nurse do first?

a. Document the EKG strips in the client's chart.

b. Contact the client's family members.

c. Call the client's clergy

d. Turn monitoring equipment off.

11. A hospitalized client has a history of chest pain. Which of the following symptoms indicates that the client has angina, instead of an MI? Choose all that apply:

a. The client's pain is relieved by morphine.

b. The client's pain is diminished by resting.

c. The client's pain was accompanied by nausea and vomiting.

d. The client's pain was alleviated after the second dose of SL nitroglycerin.

e. The client's pain was precipitated by stress. 
Appendix D: Consent to Participate

\section{CONSENT FORM}

You are invited to take part in a research study of human patient simulators and how they prepare you, the nursing student, for clinical decision-making. You were chosen for the study because you are a practical nursing student familiar with high-fidelity simulation. This form is part of a process called "informed consent" to allow you to understand this study before deciding whether to take part.

This study is being conducted by a researcher named Sharon Laney RN, MSN who is a doctoral student at Walden University. Mrs. Laney is a Coordinator of Practical Nursing at Jeff Tech in Reynoldsville, Pennsylvania.

\section{Background Information:}

The purpose of this study is to evaluate whether a simulation scenario assists in increasing your ability to make decisions at clinical better than a traditional case study.

\section{Procedures:}

If you agree to be in this study, you will be asked to:

a. View a short PowerPoint presentation concerning care of the myocardial infarction patient.

b. Complete a pre test on the PowerPoint material.

c. Participate in either a case study or a SimMan scenario.

d. Complete a post test.

e. Engage in a simulation scenario.

\section{Voluntary Nature of the Study:}

Your participation in this study is voluntary. This means that everyone will respect your decision of whether or not you want to be in the study. No one at your school (Lenape AVTS or Venango County AVTS) will treat you differently if you decide not to be in the study. If you decide to join the study now, you can still change your mind during the study. If you feel stressed during the study you may stop at any time. You may skip any questions that you feel are too personal.

\section{Risks and Benefits of Being in the Study:}

The scenario depicts a code blue emergency. Some individuals may be emotionally affected by the patient situation. All exam scores and demographic data are anonymous but there is a slight risk that exam scores could be compromised. After the research study is concluded, the results will allow your school to evaluate the effectiveness of using simulators in your curriculum. You will get to "practice" caring for a patient with acute myocardial infarctions, before you are confronted with this patient situation in the real clinical world. 
Compensation: There is no compensation for being in this study.

\section{Confidentiality:}

Any information you provide will be kept anonymous. You will be given a number to place on your exams and demographic sheet. The researcher will not even know your name during the course of the study. The researcher will not use your information for any purposes outside of this research project. Also, the researcher will not include your name or anything else that could identify you in any reports of the study.

\section{Contacts and Questions:}

You may ask any questions you have now. Or if you have questions later, you may contact the researcher via 724-549-4700 or laney@jefftech.us If you want to talk privately about your rights as a participant, you can call Dr. Leilani Endicott. She is the Walden University representative who can discuss this with you. Her phone number is 1-800-925-3368, extension 1210. The researcher will give you a copy of this form to keep. Walden University's approval number for this study is IRB will enter approval number here and it expires on IRB will enter expiration date.

\section{Statement of Consent:}

I have read the above information and I feel I understand the study well enough to make a decision about my involvement. By signing below I am agreeing to the terms described above.

Name of Participant

Signature of Participant

Name of Nursing School 
Curriculum Vitae

SHARON K. POWELL-LANEY

1372 Smyrna Road

Marion Center, PA 15759

576 Vo Tech Road

(724) 397-8329

Reynoldsville, PA 15851

PA Licensure \# 298977L

(814) 653-8420

\section{$\underline{\text { EDUCATIONAL BACKGROUND }}$}

February 2006- WALDEN UNIVERSITY

August 2010 Will receive an EdD in Educational Administration and Leadership.

Completed 54 credits at present time). Research focus is Human Patient Simulation and its' effects on the clinical decision-making ability of nursing students.

January 1993- INDIANA UNIVERSITY OF PENNSYLVANIA

May 1996 Received a Master of Science degree in Nursing Education. Graduated with a 4.0 GPA.

September 1983- INDIANA UNIVERSITY OF PENNSYLVANIA

May 1987 Received a Bachelor of Science degree in nursing and graduated cum laude from this four-year university.

\section{PROFESSIONAL EXPERIENCE}

July 1, 2001 - $\quad$ JEFFERSON COUNTY-DUBOIS AREA VOCATIONAL-TECHNICAL Present $\quad \underline{\text { SCHOOL }}$ 576 Vo Tech Road, Reynoldsville, PA 15851

Coordinator, Classroom and Clinical Instructor, Grant and Curriculum Writer, Financial Aid Director of a practical nursing program.

\section{August 2001 - $\quad$ DEAR HAVEN PERSONAL CARE HOME}

Present $\quad$ Owner and operator of a 20-bed assisted living facility.

June 1992- $\quad$ INDIANA COUNTY AREA VOCATIONAL-TECHNICAL SCHOOL July $2001 \quad 441$ Hamill Road, Indiana, PA 15701

Functioned as a nurse educator in a one-year practical nursing program. Theory courses taught included: Anatomy and Physiology, Basic Nursing Skills, Medical Terminology, IV Therapy, and Gerontology. Clinical practicum responsibilities included Medical Surgical and Geriatric rotations. 
August 1988 - INDIANA HOSPITAL

January 1991 Full-time staff nurse: responsible for the care of patients in a 13-bed medical-surgical and Cardiac Intensive Care Unit

January 1991- INDIANA HOSPITAL

June 1992 Relief charge nurse: responsible for staffing assignments and coordination of nursing activities on the 3-11 and 11-7 shift in the Intensive Care Unit.

June 1992 - $\quad$ INDIANA HOSPITAL

June 1997 Per diem staff nurse: responsible for direct patient care in the Intensive Care Unit.

May 1987 - $\quad$ UNIVERSITY OF MARYLAND SHOCK TRAUMA

June $1988 \quad 22$ S. Greene Street Baltimore, MD

Held the position of staff nurse in this position of staff nurse in this Level I trauma center.

September 1983 BEACON MANOR-FORMERLY CAMERON MANOR

-March 19871515 Wayne Avenue, Indiana, PA

Held the position of nurse's aide while attending nursing school.

$\underline{\text { PROFESSIONAL AFFILIATIONS }}$

July 2000- $\quad$ PENNSYLVANIA ASSOCIATION OF PRACTICAL NURSING

Present $\quad$ COORDINATORS

July 2000- $\quad$ PENNSYLVANIA ASSOCIATION OF STUDENT FINANCIAL AID

Present $\quad \underline{\text { ADMINISTRATORS }}$

April $1996 \quad$ PHI KAPPA PHI

Induction into this multi-disciplinary honor society at Indiana University of Pennsylvania.

November 1990 AMERICAN ASSOCIATION OF CRITICAL CARE NURSES

November 1986 SIGMA THETA TAU

International Honor Society of Nursing. Induction into the Zeta Lambda Chapter at Indiana

University of Pennsylvania 